\title{
LA RECONFIGURACIÓN TERRITORIAL DE LAS FUERZAS POLÍTICAS MEXICANAS: GEOGRAFÍA DE LA FRAGMENTACIÓN, EL COLAPSO Y LA RECOMPOSICIÓN DEL SISTEMA DE PARTIDOS $(2012-2018)^{1}$
}

\author{
THE TERRITORIAL RECONFIGURATION OF MEXICO'S \\ POLITICAL FORGES: A GEOGRAPHY OF THE \\ FRAGMENTATION, COLLAPSE AND REARRANGEMENT \\ OF THE PARTY SYSTEM (2012-2018)
}

\author{
LA RECOMPOSITION DES FORCES POLITIQUES \\ MEXICAINES: LA GÉOGRAPHIE DE LA FRAGMENTATION, \\ L'EFFONDREMENT ET LE RENOUVELLEMENT DU \\ SYSTÈME DE PARTIS (2012-2018)
}

\author{
Willibald Sonnleitner \\ El Colegio de México \\ wsonnleitner@colmex.mx
}

Resumen: En el ámbito electoral, el saldo del sexenio pasado se caracterizó por una reconfiguración radical de las fuerzas políticas, tras el colapso del sistema de partidos que estructuró la política mexicana desde la transición democrática. El opositor Movimiento Regeneración Nacional (Morena) se nutrió del hartazgo de los partidos gobernantes y se tradujo en un contundente voto de sanción. Con un enfoque espacial, esta investigación analiza los tres procesos que convergieron para producir una nueva geografía electoral en 2018: la reconfiguración socioterritorial de las fuerzas políticas; la recomposición de las coaliciones presidenciales y el voto cruzado masivo que benefició a Andrés Manuel López Obrador.

Palabras clave: elecciones; análisis espacial del voto; sistema de partidos; fragmentación política; geografía electoral.

${ }^{1}$ Agradezco las lecturas y las observaciones críticas de María Eugenia Cosío Zavala, Jesús Aguilar López y dos dictámenes anónimos, que permitieron afinar algunos de los argumentos y del análisis. 
Abstract: In the electoral realm, Enrique Peña Nieto's term in office (20122018) concluded with a radical reconfiguration of political forces, after the collapse of the party system that had structured Mexico's politics since the period of democratization. The opposition Movement of National Regeneration (Morena) grew out of grievances with governing political parties and resulted in a massive punishment vote. Through spatial analysis of voting, this research disentangles three processes that converged to produce a new electoral geography in 2018: the socio-territorial reconfiguration of political forces; the rearrangement of presidential coalitions; and substantial split-ticket voting that benefitted Andrés Manuel López Obrador.

Keywords: elections; spatial analysis of voting; party system collapse; political fragmentation; electoral geography.

\section{Traducción de Gonzalo Celorio Morayta}

RÉsumÉ: En matière électorale, le bilan du gouvernement analysé doit tenir compte d'une recomposition radicale des forces politiques, après l'effondrement du système de partis qui a guidé la politique mexicaine depuis la transition démocratique. Un acteur de l'opposition, le Mouvement de régénération nationale (Morena), a profité du mécontentement contre les partis dominants parmi la population, que celle-ci a exprimé vigoureusement par son vote punitif. Notre analyse spatiale du comportement électoral porte sur les trois processus convergents qui ont dicté une nouvelle géographie électorale en 2018: le bouleversement socio-territorial, la recomposition des coalitions pour appuyer les candidats à l'élection présidentielle et le vote «croisé» (split-ticket) massif dont a bénéficié Andrés Manuel López Obrador.

Mots clefs: Élections; analyse spatiale du comportement électoral; système de partis; fragmentation politique; géographie électorale.

Traducción de: Bernardo Mabire

Fecha de recepción: junio de 2019

Fecha de aceptación: noviembre de 2019 


\section{Un SEÍSMO SILENCIOSO [INTRODUCGIÓN]}

\section{E} n el ámbito electoral, el sexenio de Enrique Peña Nieto (2012-2018) se saldó por una reconfiguración radical de las fuerzas políticas, producto de la fragmentación paulatina y del colapso súbito del sistema tripartidista que estructuró la política mexicana desde su transición hacia elecciones plurales en la década de 1990. En su momento, los comicios presidenciales de 2012 se interpretaron como una "restauración" del Partido Revolucionario Institucional (PRI), supuestamente renovado por un grupo de jóvenes políticos unificados bajo el liderazgo del entonces gobernador del Estado de México. Seis años después, se impuso una lectura distinta. La presidencia de Peña Nieto reanudó muchas prácticas del pasado, nutriendo primero la frustración, luego el distanciamiento y por último el rechazo abierto de amplios sectores de la sociedad. En el electorado, ello se reflejó en un declive tardío, pero acentuado, sin precedentes, no sólo del tricolor sino del conjunto de partidos que gobernaron el país en las últimas tres décadas.

El triunfo de Andrés Manuel López Obrador (AMLO) en 2018, a pesar de haber sido anunciado con largos meses de anticipación, sorprendió por la amplitud de su margen de victoria. A la manera de un tsunami, el movimiento encabezado por el líder de la coalición Juntos Haremos Historia (Movimiento Regeneración Nacional, Morena-Partido del Trabajo, PT-Partido Encuentro Social, PES) arrasó con las coaliciones rivales Por México al Frente (Partido Acción Nacional, PAN-Movimiento Ciudadano, MC, MC-Partidos de la Revolución Democrática, PRD) y Todos por México (Partido Revolucionario Institucional, PRI-Partido Verde Ecologista, PVEM-Partido Nueva Alianza, Panal), encabezadas respectivamente por Ricardo Anaya Cortés y José Antonio Meade Kuribreña, relegando a un lejano cuarto lugar la candidatura independiente de Jaime Rodríguez Calderón (mejor conocido como "El Bronco"). 
La metáfora del tsunami capta el efecto masivo, inesperado y disruptivo que tuvo la tercera campaña de AMLo en las elecciones presidenciales: con más de 30 millones de sufragios, su candidatura sumó $54.8 \%$ del voto válido, rebasando a su competidor más cercano por 32 puntos porcentuales (Anaya solamente obtuvo $22.9 \%$ ) y con una ventaja de 38 puntos sobre el candidato del gobierno saliente (Meade apenas captó $16.9 \%$ ). Tras haber sumado $82.7 \%$ del sufragio en las presidenciales de 2012, el PRI, el PAN y el PRD retuvieron tan sólo $35.1 \%$ en las presidenciales de 2018, perdiendo el apoyo de seis de cada diez electores. Llevado por una oleada que arrasó con los partidos tradicionales, López Obrador obtuvo el primer lugar en 31 de los 32 estados (97\%), en 267 de los 300 distritos federales $(89 \%)$ y en 53 de las 67000 secciones electorales $(79 \%)$, sepultando así al sistema tripartidista que había organizado la política mexicana.

Sin embargo, los comicios de 2018 no pueden reducirse al voto mayoritario que agregó la coalición del nuevo presidente electo, ya que en ellos se disputaron simultáneamente 18311 cargos públicos (629 federales y 17682 locales), incluyendo la elección de ocho gubernaturas y la jefatura de la Ciudad de México, la renovación del Congreso de la Unión, de 27 legislaturas locales y de 1612 ayuntamientos. De ahí el interés de indagar en las dimensiones socioterritoriales de los comicios más grandes de la historia de México, para situar sus resultados en una perspectiva histórica y geográfica.

Para empezar, la participación electoral no fue excepcional: con $63.6 \%$ de los inscritos, ésta se situó en un promedio, entre el $77.1 \%$ alcanzado en las presidenciales de 1994 y el $58.6 \%$ de las presidenciales de 2006, en un nivel equivalente al registrado en 2000 (63.9\%) y en 2012 (63.1\%). Como en años previos, hubo entidades altamente participativas, que siempre se han caracterizado por tasas elevadas de participación (Yucatán, Campeche y la Ciudad de México; en esta última alcanzó $77 \%, 71.3 \%$ y 71.1\% en 2018), así como entidades usualmente abstencionistas, con tasas muy bajas de participación (Baja California y Chihuahua, con apenas $52.5 \%$ y $54.7 \%$, 
respectivamente). Sin embargo, también hubo cambios notables que rompieron con los patrones tradicionales de movilización electoral. Entre éstos, destaca la disminución de la participación en Guanajuato y Sonora (donde cayó por debajo de 54\%), así como el incremento de la participación en estados tradicionalmente abstencionistas, particularmente en Guerrero (64.3\%), Oaxaca (65.9\%), Chiapas (68.2\%) y Puebla $(69.4 \%)$. Ello indica que la reconfiguración de las fuerzas partidistas tuvo un carácter estructural y se acompañó de nuevas dinámicas socioterritoriales de (des)movilización electoral en el ámbito subnacional.

En segundo lugar, la fragmentación partidista se atenuó, pero no desapareció, al pasar de 5.7 a 4.4 partidos efectivos en las elecciones legislativas. Pese a la retórica de las campañas negativas que marcaron los debates presidenciales y municipales, la contienda no se polarizó en dos campos opuestos; se desenvolvió, más bien, en torno a tres coaliciones multipartidistas, en medio de una reconfiguración más compleja de la oferta política. Sería erróneo hablar de la aparición de un nuevo partido hegemónico. Impresiona que, en las presidenciales, AMLO obtuviera un porcentaje mayor de sufragios que Ernesto Zedillo en 1994 (48.7\%) y Carlos Salinas en 1988 (50.4\%) Pero, con todo y su capacidad de atraer a una miríada de electores que rompieron con el PRD, PRI, PAN u otro instituto, como partido, Morena sólo obtuvo 38.7\% en los comicios para diputados federales.

Fue así, gracias a una compleja estrategia de alianzas nacionales y regionales que, con el apoyo del PT y del PES, los candidatos de Juntos Haremos Historia ganaron las siguientes posiciones: la jefatura del gobierno de la Ciudad de México y cuatro de las ocho gubernaturas en disputa; 52 senadurías de mayoría relativa (50 de ellas en coalición y dos más bajo las siglas de Morena en Hidalgo) y 5 senadurías de primera minoría, así como 218 de las 300 diputaciones uninominales (210 en coalición y ocho más sin ella). En el ámbito municipal, en cambio, las alianzas de Morena solamente conquistaron 142 de las 1612 alcaldías en disputa (lo que, gracias a las 
coaliciones formadas desde 2015, le permite gobernar 335 municipios en la actualidad).

Aun así, la victoria de Morena fue contundente. Además de las derrotas personales de Ricardo Anaya y José Antonio Meade en las presidenciales, tanto el PAN (18.7\%) como el PRI $(17.2 \%)$ pero sobre todo el PRD $(5.5 \%)$, tocaron fondo en las elecciones para diputados. Se evidenció, también, la debilidad del Panal y del pes (que no alcanzaron el umbral legal de $3 \%$ y perdieron su registro nacional), así como la concentración geográfica del PVEM, del MC y del PT que, pese a la influencia que ejercen en algunos municipios, distritos o entidades, apenas sumaron $5 \%, 4.6 \%$ y $4.1 \%$ del sufragio nacional.

En otras palabras, Morena captó una masa crítica pero amorfa de desencantados que abandonaron sus antiguas lealtades para apostarle a una nueva opción política, multiplicando su caudal electoral por cinco solamente en tres años. Desde esta perspectiva, el tsunami electoral es el producto de una profunda transformación de la demanda política. La oleada resultó de un movimiento telúrico que se produjo antes de que ésta se formara y expandiera, tocara tierra e inundara las urnas en 2018. Para ser precisos, el terremoto que causó el colapso del PRD, del PRI y del PAN fue antecedido de un paulatino proceso de descomposición que -como lo mostramos en investigaciones anteriores- ${ }^{2}$ se remonta al menos a las legislativas intermedias de 2003. El terremoto que causó el colapso del PRD, del PRI y del PAN fue antecedido de un paulatino proceso de descomposición partidista que se remonta, por lo menos, a las legislativas intermedias de 2003. Más allá de la coyuntura, asistimos así a una

${ }^{2}$ Véase, en particular Willibald Sonnleitner, "Rastreando las dinámicas territoriales de la fragmentación partidista en México (19912015)", América Latina hoy, Revista de Ciencias Sociales, vol. 75, abril de 2017; así como Willibald Sonnleitner, Lo que el voto se llevó. La descomposición del pacto posrevolucionario en México, México, El Colegio de México, 2018, 395 pp. 
reconfiguración estructural de las fuerzas políticas, cuyas bases merecen ser estudiadas en el ámbito subnacional.

Más que constituir un nuevo partido hegemónico, el movimiento encabezado por AMLo puso de manifiesto el hartazgo con las elites y el rechazo generalizado de los partidos gobernantes, que se tradujo en un voto de sanción rotundo. Para separar lo estructural de lo coyuntural, distinguimos tres fenómenos con temporalidades propias que convergieron en 2018: 1) la reconfiguración territorial de las fuerzas políticas, producto de la fragmentación y del colapso del antiguo sistema de partidos; 2) la renegociación de las alianzas tras las rupturas que propició la designación de las candidaturas presidenciales y la realineación de los liderazgos en torno a ellas, y 3) los efectos de atracción/rechazo de los candidatos presidenciales, que se reflejaron en un voto cruzado masivo, en detrimento de Meade y de Anaya, y en beneficio del Bronco pero, sobre todo, de López Obrador.

Para facilitar la comprensión de este rompecabezas electoral, iniciamos con los cambios estructurales más profundos; luego, indagamos en las rupturas y recomposiciones entre las elites partidistas, nacionales y regionales, para concluir con el voto cruzado. Desde un punto de vista metodológico, recurrimos a diversas técnicas estadísticas y de análisis espacial de los resultados electorales, para desentrañar las dinámicas territoriales de la reconfiguración del voto en el nivel de las 32 entidades y de los 300 distritos federales. ${ }^{3}$ Asimismo, nos apoyamos

${ }^{3}$ Todos los mapas fueron elaborados por el autor, con el programa Philcarto (http:// philcarto.free.fr/Telechargement.html), con base en los resultados oficiales publicados por el Instituto Federal Electoral, IFE, Atlas Electoral Federal de México (1991-2012), México, IfE, 2012, y por el Instituto Nacional Electoral, INE, Sistema de Consulta de la Estadística de las Elecciones Federales (Siceef), en línea: http:/ /www.ine.mx/voto-y-elecciones/resultados-electorales/ (consulta del 25 de mayo de 2019). Los datos sociodemográficos provienen del Instituto Nacional de Estadística y del Instituto Federal Electoral, Sistema Estadísticas Censales a Escalas Geoelectorales, datos del Censo de Población y Vivienda 2010 a nivel de Distrito y Sección electoral, México, 2012 (Inegi- IFE, 2012), y están disponibles en línea: http://gaia.inegi.org.mx/geoelectoral/viewer.html 
en estudios de casos subnacionales y en el análisis de la encuesta de Berumen e Ipsos entre el 30 de mayo y el 6 de junio de $2018 .^{4}$

\section{RASTREANDO LOS ORÍGENES Y LA LONGITUD DEL TSUNAMI ELECTORAL}

Cuando se observa en una óptica superficial, a través del total de sufragios que logró agregar AMLo en 2018, la magnitud del cambio resulta asombrosa: tras haber obtenido el cuarto lugar, con $7.8 \%$ del voto bajo las siglas de Morena en 2015, su coalición presidencial sumó 54.8\%, incrementando su caudal electoral en $700 \%$ en solamente tres años. Sin embargo, una transformación de tal magnitud no puede explicarse únicamente por el carisma de una persona. El tsunami electoral es el producto de cambios estructurales profundos que pueden analizarse en tres momentos consecutivos.

Además de las diversas técnicas estadísticas para explorar los datos con distintos criterios analíticos, recurrimos al análisis de clasificación jerárquica ascendente (CJA) para agrupar las unidades territoriales minimizando la varianza interna de los promedios de cada categoría, maximizando a la vez su diferenciación con respecto al resto de categorías. Ello permite conglomerar los casos más similares e identificar los casos atípicos, ubicando las principales lógicas de su distribución y sus fronteras geográficas mediante la construcción de mapas de síntesis. Véase Erwann Minvielle y Souiah Sid-Ahmed, L'analyse statistique et spatiale. Statistiques, cartographie, télédétection, SIG, Nantes, Éditions du temps, 2003, pp. 61-82.

${ }^{4}$ Dicha encuesta fue financiada por la Fundación Este país y realizada por Berumen e Ipsos (que se alternaron en el levantamiento y el control del trabajo de campo). Incluye 13317 entrevistas individuales, con sobremuestras para las nueve entidades que eligieron gobernadores. La calidad de los datos se refleja en sus proyecciones (AMLO obtiene $54.1 \%$ de las 10258 preferencias electorales declaradas). La base de datos está en el sitio web del INE: https://www.ine.mx/voto-y-elecciones/encuestas-elec torales/elecciones-federales-ordinarias-2017-2018-estudios-entregados/ berumen-2/ (consulta del 20 de mayo de 2019). 
De la fragmentación al colapso del tripartidismo (1997-2018)

Para obtener una perspectiva temporal de mediano plazo, la gráfica 1 sintetiza las características y la magnitud del terremoto político en el nivel nacional. Partimos de los promedios del PRI, del PAN y del PRD en los cuatro comicios para diputados federales celebrados entre 1997 y 2006 ("97-06D”). Como muy pocos mexicanos conocen a los candidatos que compiten en los distritos uninominales, los resultados de estas elecciones relativamente anónimas proporcionan una aproximación de la fuerza estructural de los partidos. A partir de 2009 consideramos estos resultados tanto en las elecciones para senadores ("S") y diputados federales ("D") como en las elecciones presidenciales ("P"), que reflejan la popularidad de los distintos candidatos. Esto nos permite observar la magnitud del voto cruzado entre los distintos tipos de elecciones en 2012 y 2018. Finalmente, reportamos tanto los resultados registrados por cada partido por separado (adjudicándole la parte de votos que le corresponde por concepto de coaliciones), como las sumas obtenidas por las principales alianzas (“-Al”), para visualizar los efectos de las estrategias de coaliciones.

Ante todo, se observa el ascenso exponencial de Morena entre su primera participación en las legislativas de 2015 y la victoria avasalladora de su candidato presidencial en 2018, que arrasó con las candidaturas de los partidos tradicionales a la manera de una gigantesca ola de repudio electoral. Sin embargo, cabe distinguir entre los resultados de los distintos tipos de comicios, de los partidos y de las alianzas: mientras que la coalición de AMLo triunfó con $54.8 \%$ del voto válido presidencial, ésta solamente obtuvo $45.4 \%$ del sufragio para diputados, lo que reveló el peso del voto cruzado. A su vez, Morena apenas captó $38.8 \%$ en las legislativas del mismo año, lo que obliga a considerar el peso específico de sus aliados (véase gráfica 1).

En efecto, persiste una gran fragmentación en un contexto de impresionante volatilidad. Es en este momento peculiar -de hartazgo generalizado con la clase política gobernante- 
que triunfa el movimiento opositor encabezado por López Obrador. Y es en esta coyuntura crítica y excepcional -de colapso del sistema tradicional de partidos- que Morena incrementa su electorado en $500 \%$ en tan sólo tres años. Este crecimiento no puede explicarse sin captar el declive profundo del PRD, del PRI y, en menor medida, del PAN. Para entender el origen y las características de este nuevo electorado, observemos los reportes de votos durante el sexenio pasado, analizando cada partido por separado.

\section{GRÁFICA 1}

Tendencias históricas y transferencias de votos (1997-2018)

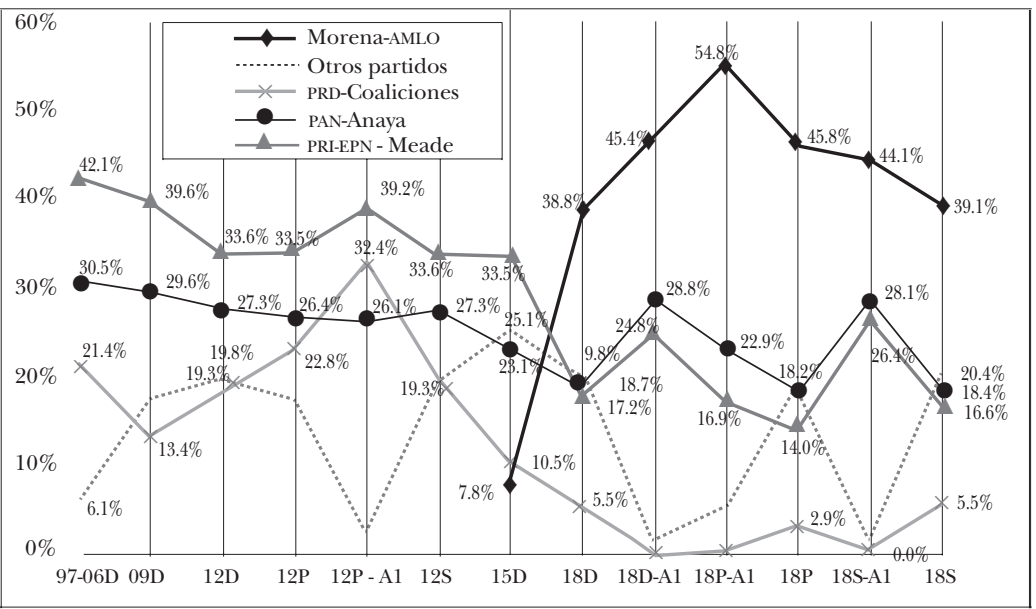

Fuente: elaboración propia con base en los resultados electorales definitivos del IFE (2012) y del INE (2018). "D"= Diputados; "P"= Presidentes; "S"= Senadores; "Al"= Alianzas.

El caso más evidente es el del PRD. Gracias al arrastre de la candidatura del mismo AMLO, éste obtuvo $19.3 \%$ en las elecciones para diputados y le aportó 22.8 puntos a la coalición "Por el Bien de Todos" en las presidenciales de 2012. La ruptura de AMLO con la dirigencia perredista después de que 
ésta se sumara al Pacto por México del presidente Peña Nieto catalizó la transformación de Morena en partido político en 2014 y se saldó por una pérdida masiva de electores en 2015, cuando el PRD sólo obtuvo $10.5 \%$ del sufragio. Una parte importante de quienes votaron por Morena en 2015 proviene de estos sectores, pero la composición de dicho electorado es más heterogénea y compleja.

El PRD sufrió una segunda sangría en 2018, cuando obtuvo $5.5 \%$ del sufragio para diputados y apenas captó $2.9 \%$ en las presidenciales, tras haberse sumado a la coalición y a la candidatura panista de Ricardo Anaya. Su declive se produjo así, sobre todo, en los primeros tres años (cuando perdió 8.8 puntos porcentuales) y se mantuvo a lo largo del sexenio (con una caída adicional de 5 puntos entre 2015 y 2018), registrando dos pérdidas consecutivas de la mitad de sus electores por trienio.

El declive del PRI resulta menos dramático en términos relativos, pero es crucial en cuanto a lo sustantivo. Con todo y los escándalos de corrupción, de la fuga de varios gobernadores priistas, de la "Casa Blanca" y de las protestas masivas por la desaparición de los estudiantes de Ayotzinapa, la fuerza del partido parecía intacta hasta 2015. Las percepciones cambiaron drásticamente en el segundo trienio y el tricolor pasó de $33.5 \%$ a $17.2 \%$ del voto, registrando una pérdida mayor a las del PRD durante todo el sexenio (-16.3 puntos porcentuales). Sus resultados fueron aun peores en las presidenciales, en las que Juntos por México sumó $16.9 \%$ pero el PRI apenas obtuvo $14 \%$ del sufragio. Las alianzas con el PVEM y con el Panal atenuaron la derrota en las legislativas, pero no frenaron la debacle personal de José Antonio Meade, quien obtuvo ocho puntos menos que los aspirantes a diputados de su coalición.

El PAN resistió un poco mejor. Tras haber obtenido $27.3 \%$ en las legislativas de 2012, sufrió dos pérdidas consecutivas de cuatro y una disminución total de 8.6 puntos a lo largo del sexenio. Sus alianzas con el PRD y el MC también amortiguaron su caída en las legislativas de 2018, aunque Ricardo Anaya tampoco resultó atractivo y registró 5.8 puntos menos que los candidatos a diputados de su coalición. Como vere- 
mos posteriormente, el voto cruzado panista benefició en parte a Meade y al Bronco, pero también a AMLO, pese a las divergencias discursivas e ideológicas de las campañas y los debates presidenciales.

Las transferencias de votos entre el resto de partidos, en cambio, no tuvieron un papel disruptivo en la reconfiguración de la política nacional, pese al nivel elevado de fragmentación. Hubo cambios sustantivos en la composición regional de estas fuerzas en algunas entidades, particularmente en Chiapas (donde el PVEM se transformó en la fuerza principal cuando Manuel Velasco ganó la gubernatura en 2012), Nuevo León (gobernado desde 2015 por Jaime Rodríguez, quien, tras haber roto con el PRI se presenta como independiente) y Jalisco (donde Enrique Alfaro ganó la gubernatura en 2018 con las siglas del MC); volveremos sobre su importancia creciente en la política subnacional. Destaquemos, por ahora, que en su conjunto éstos sumaron $19.8 \%$ del sufragio tanto en las legislativas de 2012 como en las de 2018. Se trata, no obstante, de un componente fundamental para la formación de coaliciones competitivas, con un peso territorial que varía considerablemente a lo largo y ancho del país.

En suma, el incremento exponencial de Morena se explica por la fragmentación, por el declive y el colapso de los tres partidos que venían estructurando la política mexicana desde la década de los noventa. Entre las legislativas del inicio y las del final del sexenio, el PRI, el PRD y el PAN perdieron 16.4, 13.8 y 8.6 puntos porcentuales respectivamente. Considerando el peso desigual de los resultados que obtuvieron en 2012, esto significa que siete de cada diez electores perredistas, cinco de cada diez electores priistas y tres de cada diez panistas rompieron esos partidos para sufragar por opciones alternativas en las legislativas de 2018. Como la proporción total del resto de partidos no varió, tales transferencias masivas de votos se reportaron esencialmente sobre Morena, partido que logró captar $38.8 \%$ del voto para diputados al concluir el sexenio. Este fenómeno obedeció a diversas lógicas subnacionales que analizaremos ahora con mayor detenimiento. 
Como botón de muestra, las gráficas 2 a 7 ilustran la heterogeneidad de las dinámicas estatales mediante seis casos contrastantes. Mientras que en la Ciudad de México, el crecimiento de Morena se explica fundamentalmente por la división y por el declive del PRD, en Tabasco su ascenso meteórico resulta del colapso del bipartidismo PRI-PRD, que también arrasa con el resto de partidos. En Nayarit, en cambio, Morena se nutre directamente de la caída estrepitosa del PRI, con una lógica opuesta a la de Campeche, donde sus nuevos electores provienen sobre todo del PAN. En Guanajuato, Acción Nacional resiste a los embates del tsunami electoral y AMLO se beneficia, sobre todo, de una impresionante volatilidad del PRI y del resto de partidos. En Chiapas, finalmente, Morena crece en un contexto de impresionante volatilidad electoral, producto de la fragmentación que prevalece desde que colapsa el sistema de partidos local en 2012 (véase gráficas 2 a 7).

\section{GrÁfICA 2}

Seis dinámicas estatales contrastes (1997-2018)

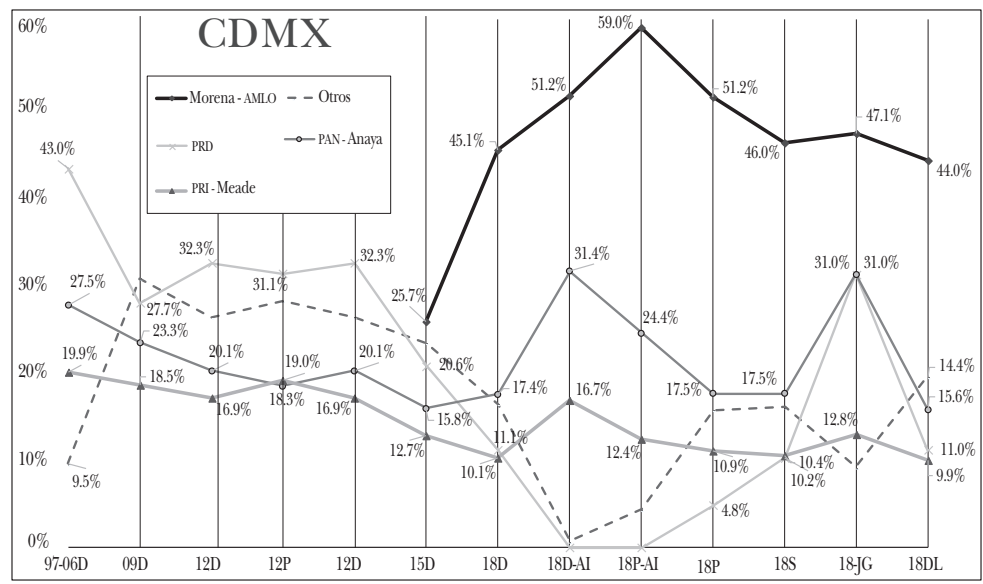

Fuente: elaboración propia con base en los resultados electorales definitivos del IFE (2012) y del INE (2018). "D"= Diputados; "P"= Presidentes; "S"= Senadores; "Al"= Alianzas. 


\section{GrÁFICA 3}

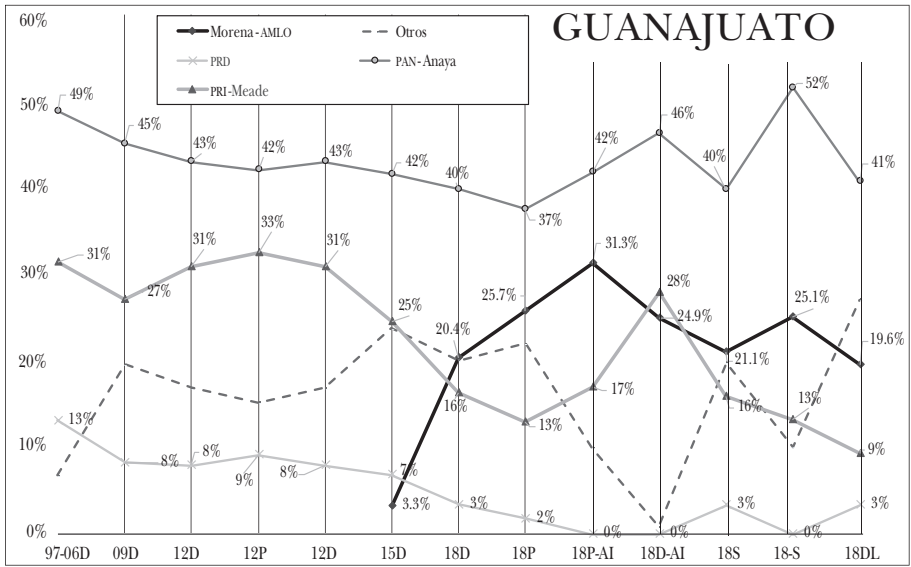

Fuente: elaboración propia con base en los resultados electorales definitivos del IFE (2012) y del INE (2018). "D"= Diputados; "P"= Presidentes; "S"= Senadores; "Al"= Alianzas.

\section{GrÁfICA 4}

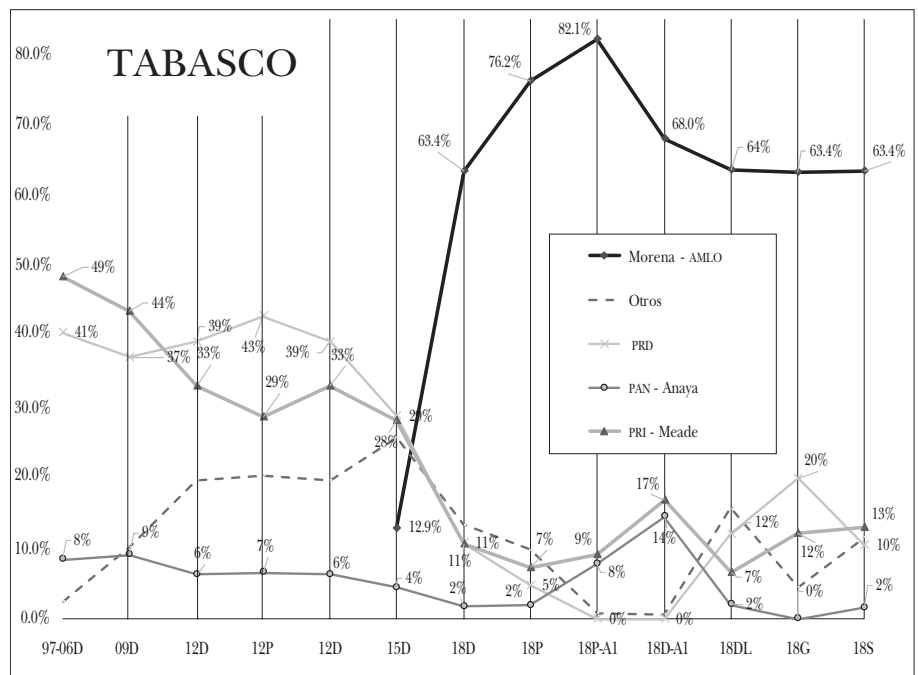

Fuente: elaboración propia con base en los resultados electorales definitivos del IFE (2012) y del INE (2018). "D"= Diputados; "P"= Presidentes; "S"= Senadores; "Al"= Alianzas. 


\section{GrÁFICA 5}

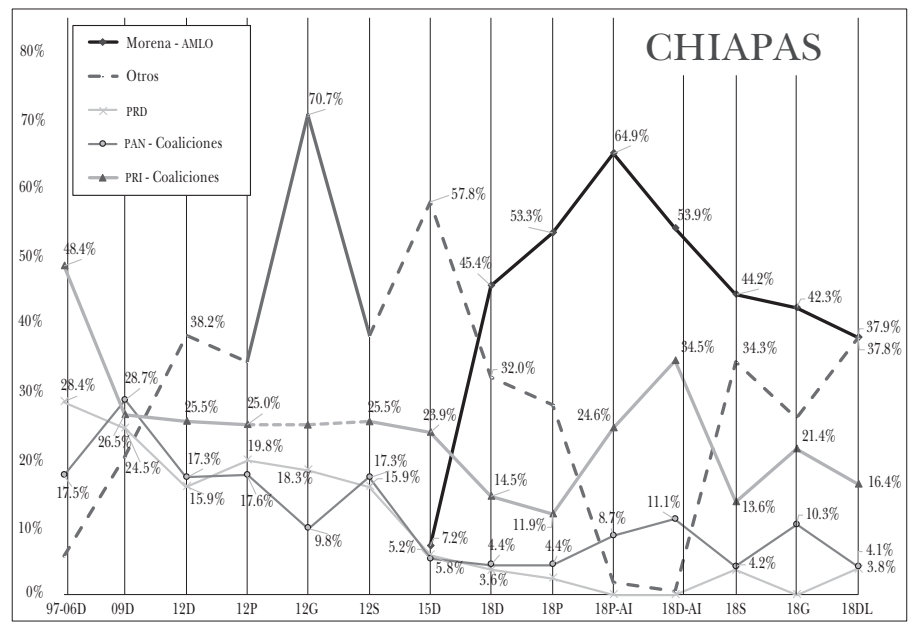

Fuente: elaboración propia con base en los resultados electorales definitivos del IFE (2012) y del INE (2018). "D"= Diputados; "P"= Presidentes; "S"= Senadores; "Al"= Alianzas.

\section{Gráfica 6}

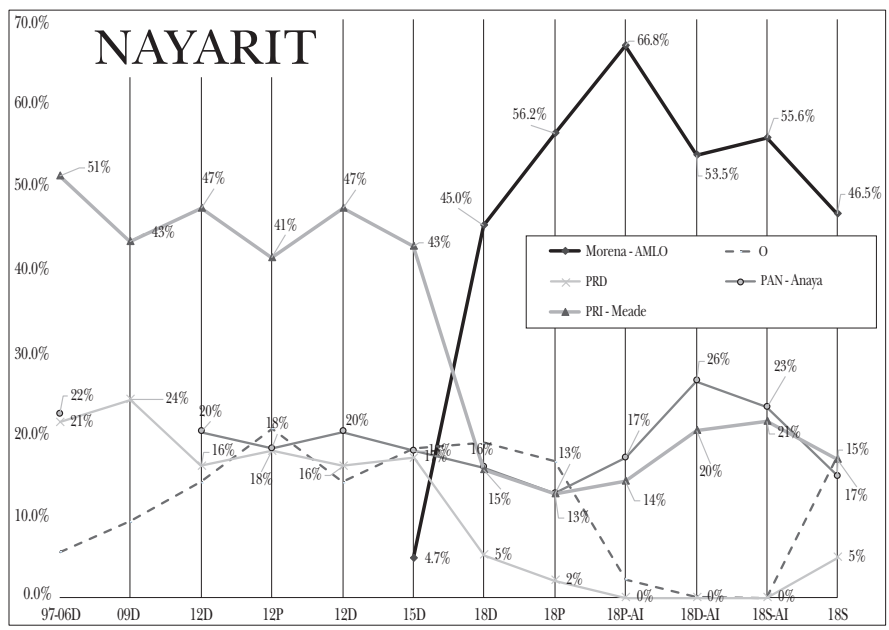

Fuente: elaboración propia con base en los resultados electorales definitivos del IFE (2012) y del INE (2018). "D"= Diputados; "P"= Presidentes; "S"= Senadores; "Al"= Alianzas. 


\section{GRÁFICA 7}

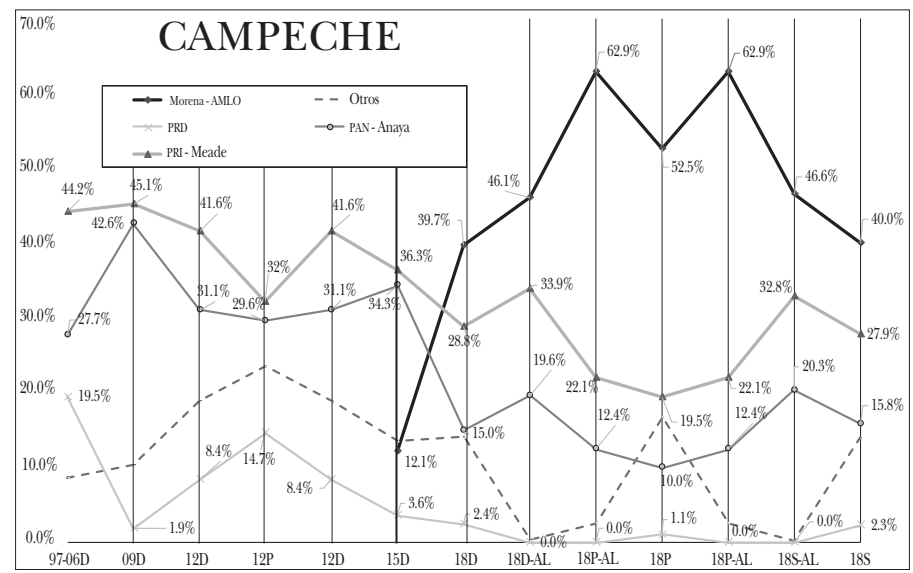

Fuente: elaboración propia con base en los resultados electorales definitivos del IFE (2012) y del INE (2018). "D"= Diputados; "P"= Presidentes; "S"= Senadores; "Al"= Alianzas.

Sin embargo, para interpretar el tsunami sin reducirlo a la suma de 32 procesos desconectados, cabe analizar ahora cómo encajan las distintas piezas del rompecabezas dentro de la nueva geografía electoral, con un enfoque y en una perspectiva nacional.

Volatilidad electoral y transferencias estatales de votos (2012-2018)

Para captar las raíces de este terremoto silencioso, estudiemos ahora las transferencias de votos en el nivel de las 32 entidades. El mapa 1 proporciona un buen punto de partida, al sintetizar la correlación de fuerzas en las elecciones presidenciales y para diputados federales de 2012. En vistas de identificar las bases territoriales del PRI, del PAN y del PRD, nos enfocamos en los sufragios obtenidos por estos partidos, agrupando el resto de los institutos en una categoría residual denominada "Otros". 
Cuando Peña ganó la presidencia de la República, el PRI contaba con una amplia ventaja en cinco estados norteños (Chihuahua, Durango, Zacatecas, Sinaloa y Nayarit) y en Hidalgo (C03). Asimismo, competía en condiciones ventajosas con el PAN en Baja California Sur, Jalisco, Aguascalientes, San Luis Potosí y Campeche (C01), y con el PRD en el Estado de México, Michoacán, Guerrero, Oaxaca y Tabasco (C04). También tenía bases sólidas en las nueve entidades con fuerte presencia panista, en Sonora, Coahuila, Nuevo León, Tamaulipas, Veracruz, Yucatán, Guanajuato, Querétaro y Colima (C05). Sus peores resultados se concentraban, entonces, en los siete estados con mayor fragmentación partidista (C02), donde los sufragios se dividieron en cuatro partes de proporciones similares (véase mapa 1).

Al concluir el sexenio, la situación fue radicalmente distinta. Las transferencias más intuitivas se registraron desde el PRD hacia Morena y fueron particularmente marcadas en Tabasco, Oaxaca, Guerrero y la Ciudad de México (C05, donde éste pierde 22.2 puntos porcentuales al caer de $33.7 \%$ a $11.5 \%$ ). Éstas también son notables en siete entidades más, en las que el partido del Sol Azteca (PRD) pasa de $19.1 \%$ a $4.9 \%$ (C02: Estado de México, Morelos, Puebla, Tlaxcala, Quintana Roo y Chiapas). Pero estos reportes de votos son insuficientes para explicar el crecimiento total de Morena, que registra promedios superiores a $45 \%$ en ambas categorías de entidades. Por ende, incluso en estos estados con fuerte presencia perredista se produce un declive muy notable del PRI (mayor a -13 puntos porcentuales), del PAN (superior a -6.4 puntos) y del resto de partidos (véase mapa 2). 


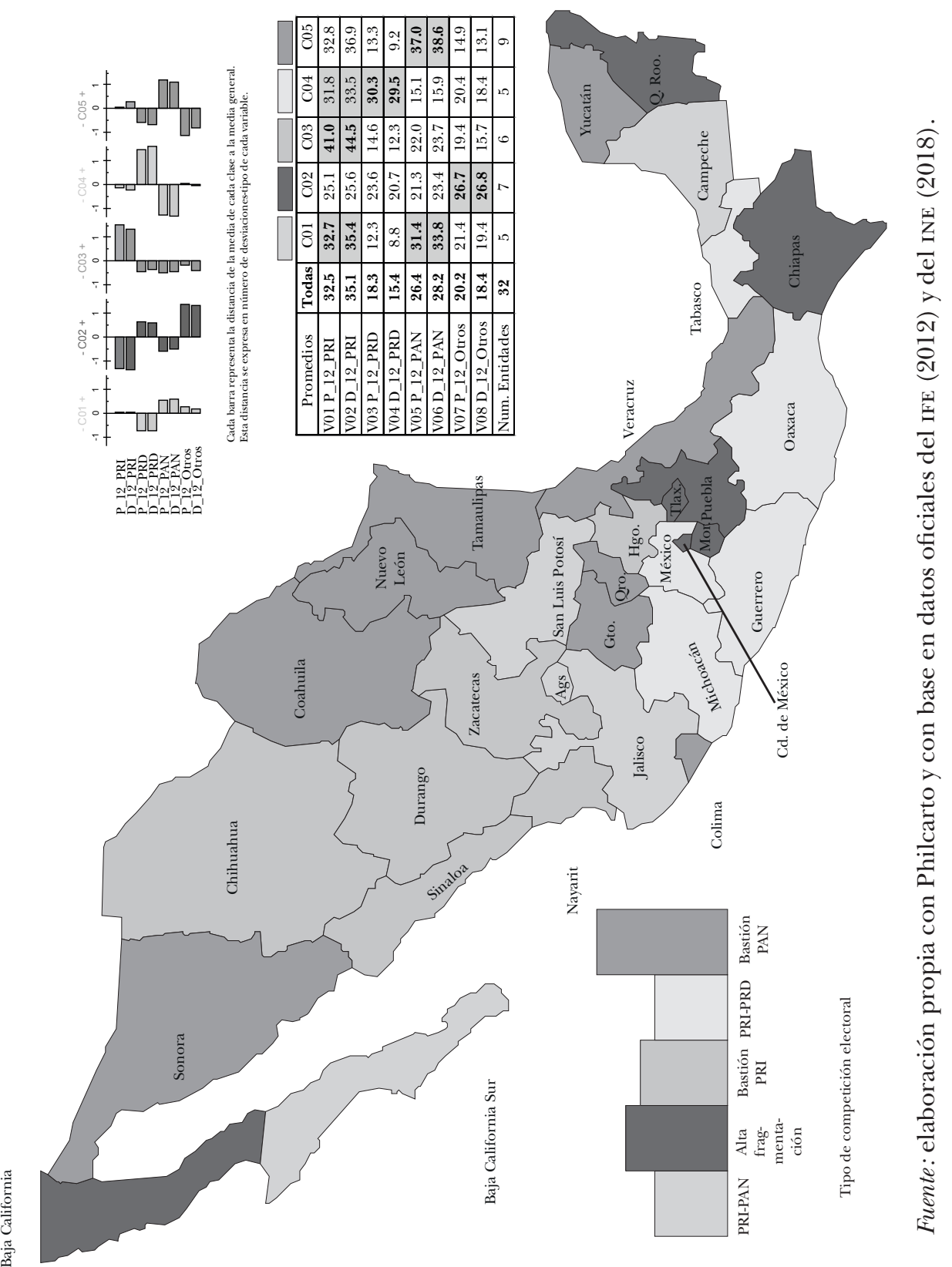




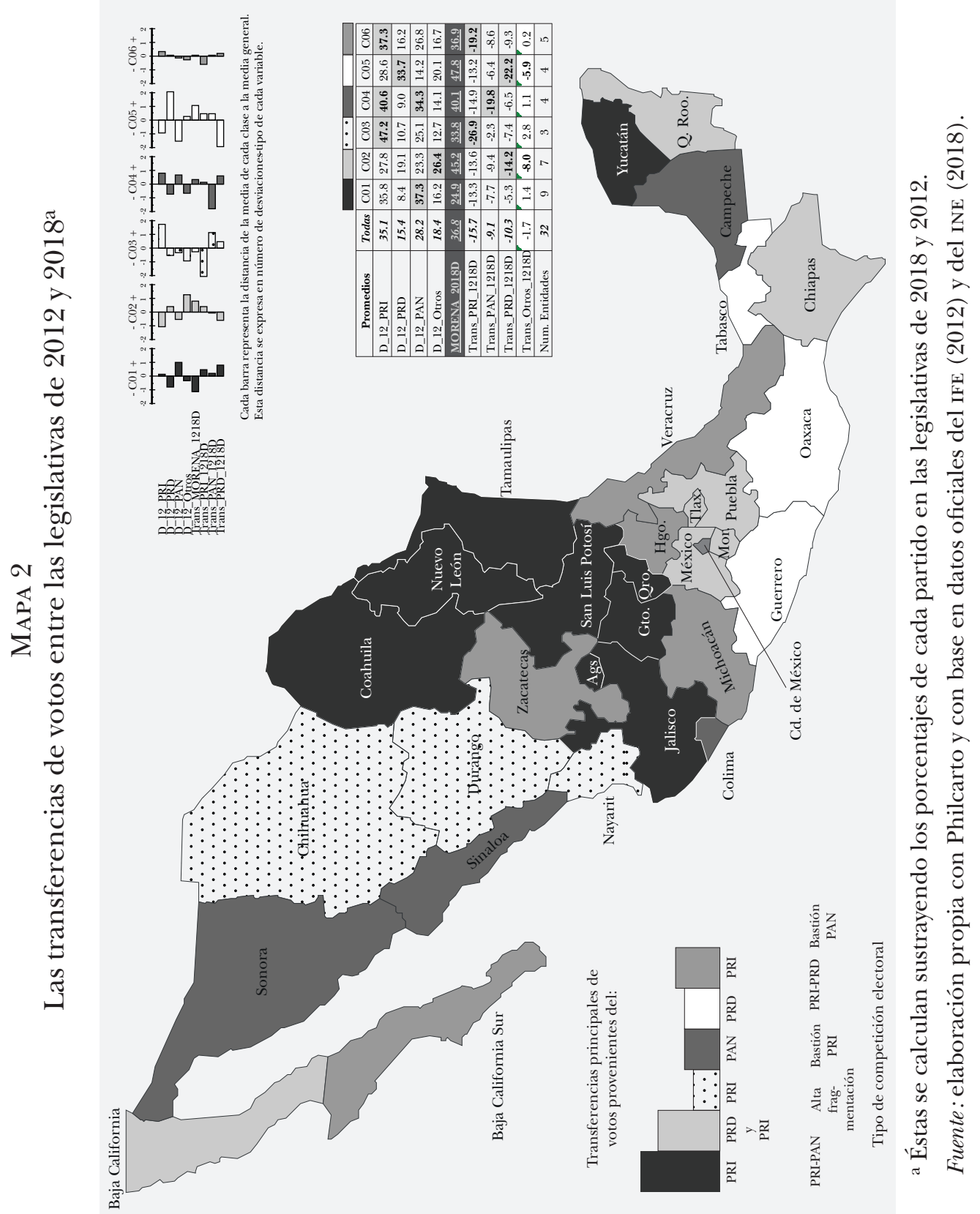


Como también se observa en el mapa 2, el declive más drástico del PRI se produjo en Chihuahua, Durango y Nayarit (C03, donde éste obtuvo un promedio de $47.2 \%$ en 2012 y bajó -26.9 puntos durante el sexenio). El PRI también perdió a la mitad de sus electores en dos de sus antiguos bastiones (Hidalgo y Veracruz) y en tres estados que fueron gobernados por el PRD (Michoacán, Zacatecas y Baja California Sur), donde pasó de un promedio de $37.3 \%$ en 2012 a $18.1 \%$ en 2018 (C06).

El declive del PAN se concentró en cuatro entidades (Sonora, Sinaloa, Colima y Campeche) donde el blanquiazul pasó de $34.3 \%$ a $14.5 \%$ (-19.8 puntos porcentuales), con lo que rebasó las pérdidas del PRI (-14.9 puntos) en las mismas entidades. Tan sólo en Jalisco, Aguascalientes, Guanajuato, Querétaro, San Luis Potosí, Tamaulipas, Nuevo León, Coahuila y Yucatán (C01), el declive del PAN y del PRD fue menos acentuado, por lo que Morena sólo captó una cuarta parte del electorado de estas nueve entidades con fuerte presencia panista. Con la excepción de esta franja, lo que se observó fue una transferencia masiva y generalizada de votos hacia Morena, que no solamente atrajo tres de cada cuatro sufragios perredistas y uno de cada dos sufragios priistas, sino que logró arrebatarle tres de cada diez electores al PAN (véase mapa 2).

Lejos de contrarrestar el crecimiento de Morena, las bases territoriales del PRI y del PRD se dividieron y sumaron al proyecto alternativo. En el caso del tricolor, los desprendimientos se produjeron en todas las entidades y alcanzaron proporciones sorprendentes en Chihuahua, Durango y Nayarit. En el caso del PRD, también se produjo de forma generalizada, pero se concentraron en cuatro de sus antiguos bastiones (Ciudad de México, Tabasco, Oaxaca y Guerrero). Sólo el PAN rompió con esta tendencia y resistió mejor en nueve de sus bastiones tradicionales, ya que sus pérdidas se concentraron en cuatro entidades con fuerte presencia priista (Sonora, Sinaloa, Colima y Campeche). En todo caso, impresiona la magnitud de los cambios, que remoldean profundamente la geografía electoral estatal de México. 


\section{DE LA FRAGMENTACIÓN A LA RECONFIGURACIÓN DE LAS FUERZAS PARTIDISTAS}

En segundo lugar, cabe indagar en las características y efectos que tuvieron las distintas alianzas electorales, partiendo de las estrategias y decisiones que tomaron las direcciones nacionales en la negociación de las coaliciones presidenciales, pero considerando, asimismo, el peso territorial de las distintas fuerzas partidistas en el nivel de los distritos uninominales, en un contexto de fuerte fragmentación partidista. Recordemos brevemente la geografía que surgió de las legislativas federales intermedias de 2015, que sirvió de referencia para las negociaciones de las alianzas presidenciales en 2017-2018.

Las bases territoriales de los “pequeños" partidos políticos en 2015

Los comicios legislativos de 2015 pasaron inadvertidos por la mayoría de los observadores, porque el PRI se mantuvo sorprendentemente estable pese a los escándalos de corrupción y a la tragedia de Ayotzinapa. Sus resultados revelan, sin embargo, las fisuras del pacto negociado por los principales partidos de gobierno. El mapa 3 sitúa los 200 distritos en los que el PRI, el PAN y el PRD todavía tienen una presencia sólida en 2015, así como los 100 restantes donde las otras fuerzas partidistas ya se han vuelto mayoritarias. Estos últimos se concentran en Quintana Roo, Chiapas, Morelos y la Ciudad de México, pero también se ubican en otras regiones del sureste, centro, Bajío y norte del país.

Profundicemos brevemente en el análisis de las bases territoriales de los partidos "pequeños" en 2015. Gracias a una sutil estrategia de coaliciones locales y regionales, el PVEM logró crecer desde que participa en la Alianza por el cambio de Vicente Fox en el 2000. Invisibilizada por la estructura de la boleta hasta 2006 (que impedía distinguir entre partidos coaligados), su expansión le permitió conquistar la guberna- 
tura de Chiapas bajo el liderazgo del joven senador Manuel Velasco Coello en 2012, transformándose en la primera fuerza del estado. En 2015, el Verde consolidó su presencia y obtuvo entre $31 \%$ y $59 \%$ del sufragio en los doce distritos de la misma entidad. Ello se tradujo en una fuerte concentración territorial (con un índice de Moran de 0.75) ya que el PVEM obtuvo $26.2 \%$ de su voto nacional en Chiapas (es decir, 7.8 veces más que en los distritos restantes).

Como sucesor de Convergencia Democrática, el Mc también cuenta con una larga pero débil presencia nacional, antes de crecer de una forma sostenida gracias al liderazgo carismático de Enrique Alfaro en Jalisco. En 2015, este partido arrasó en doce distritos situados no solamente en Guadalajara y Puerto Vallarta, Jalisco, sino también en Ciudad Victoria, Tampico, donde sumó entre $33.2 \%$ y $44.2 \%$ de los votos (que representan $27.4 \%$ del total que obtuvo el Mc a nivel nacional).

Nueva Alianza se fundó en 2005, bajo el liderazgo de la maestra Elba Esther Gordillo y con el apoyo activo del Sindicato Nacional de Trabajadores de la Educación (SNTE), uno de los más grandes y poderosos de Latinoamérica. Desde entonces, el Panal ha participado en coaliciones coyunturales de la más diversa índole pero también se implantó en algunos municipios. En 2015 consiguió buenos resultados en nueve distritos de Aguascalientes, Hidalgo, Morelos, Puebla y Oaxaca, con bases mucho más volátiles y dispersas que las del Verde y del ma.

Lo mismo sucede con el Partido del Trabajo (PT), que ha tenido una presencia discreta pero constante desde su fundación en 1990. Gracias a una serie de coaliciones con el PRD, logró conservar su registro y ha gobernado decenas de municipios. En 2015, el PT obtuvo resultados notables en 18 distritos de Baja California, Zacatecas, Michoacán, el Estado de México, Morelos, Guerrero, Veracruz y Tabasco, así como en La Paz, Mazatlán y Victoria de Durango, con entre $7.2 \%$ y hasta $25.6 \%$ de los sufragios válidos, que representan una cuarta parte de su electorado nacional. 


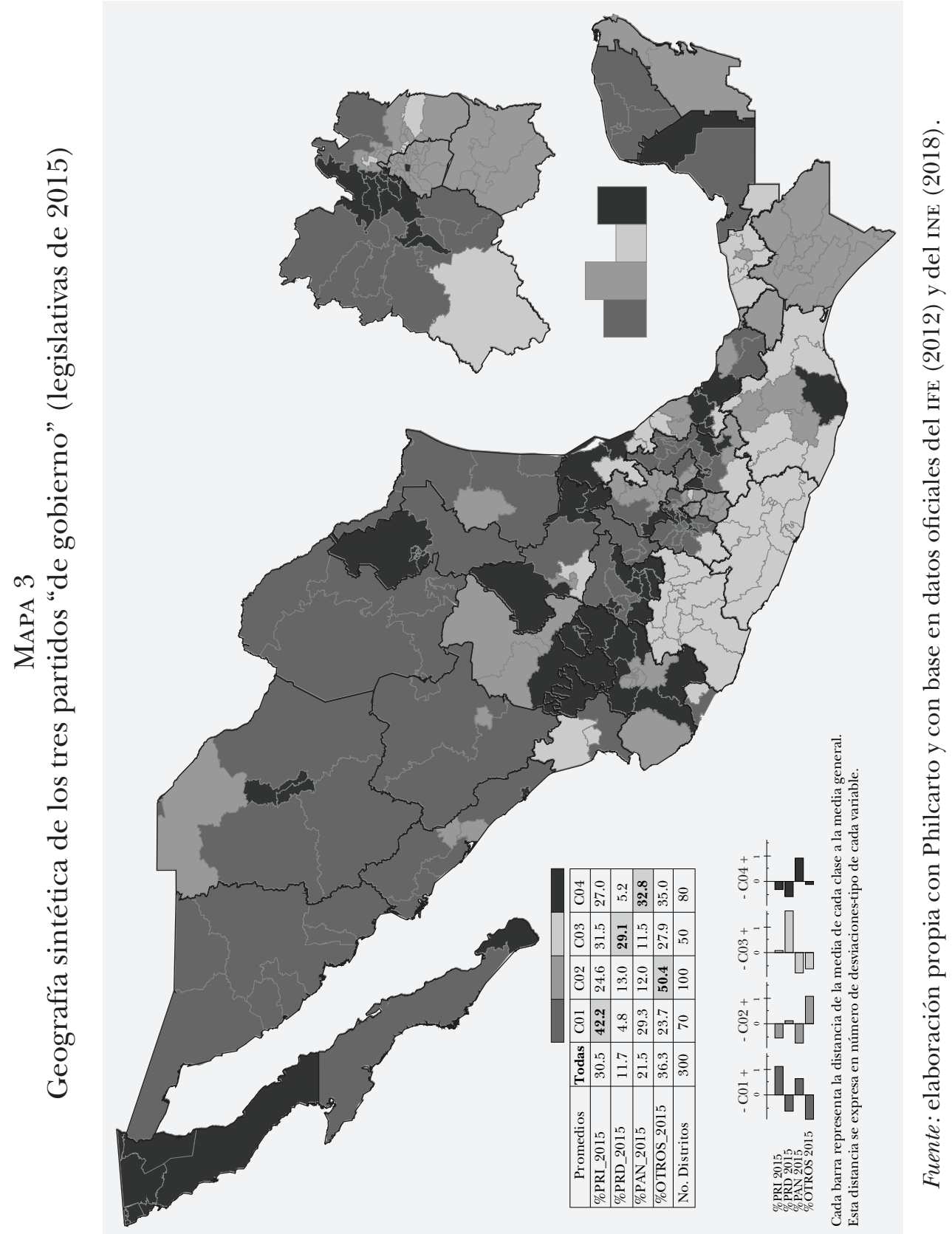




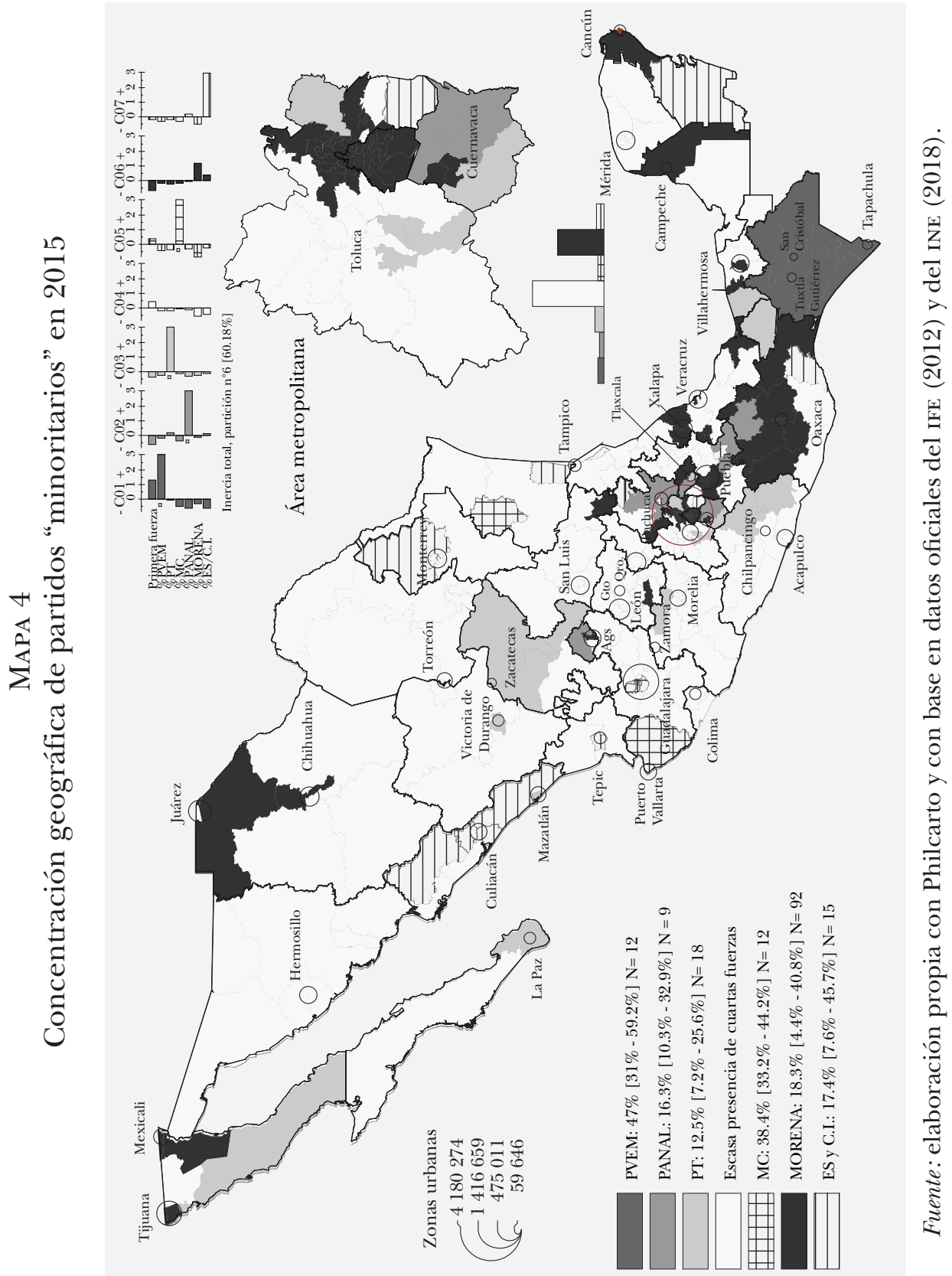


A su vez, el voto de Encuentro Social y de algunos candidatos independientes se concentró en 15 distritos más, donde sumaron entre $7.6 \%$ y $45.7 \%$ de los votos válidos. Su presencia es notoria en Sinaloa (donde Manuel Clouthier conquista una diputación federal) y en Monterrey (donde la victoria de "El Bronco" a la gubernatura de Nuevo León ejerce efectos de arrastre en las legislativas), pero también se observó en un puñado de distritos dispersos de Hidalgo, Estado de México, Puebla, Oaxaca y Chetumal, sin caracterizarse por una dinámica espacial coherente.

Pero es, sobre todo, la distribución geográfica de Regeneración Nacional que merece analizarse en el nivel distrital. Sin sorpresas, el nuevo partido creció exponencialmente en la Ciudad de México, pero su presencia se extendió de entrada a 92 distritos donde obtuvo entre $4.4 \%$ y hasta $40.8 \%$ del sufragio, es decir el $55.6 \%$ de su voto total (véase mapa 4). Sin ser todavía una fuerza de alcance nacional, en 2015 Morena registró resultados notables en el norte (Tijuana, Mexicali, Ciudad Juárez y Chihuahua), en el centro (valle de México, Cuernavaca, Puebla e Hidalgo) así como en el sureste del país (particularmente en Oaxaca y Veracruz, pero también en Villahermosa, Campeche y Cancún). Sin duda, la concentración territorial de sus votos (índice de Moran de 0.66) representaba entonces aun un hándicap, que AMLO compensaría mediante una gira permanente para promover su candidatura presidencial.

De una forma discreta, la descomposición partidista se profundizó en los comicios locales subsecuentes de 2016 y 2017, en los que Morena siguió expandiéndose a lo largo y ancho del territorio nacional. Según el seguimiento de Navarrete Vela, este partido apenas obtuvo 2.9\% de los sufragios válidos en las elecciones para gobernadores de 2015, pero pasó a un promedio de $13 \%$ en aquellas que se celebran en 2016 y captó 27.3\% de los votos emitidos en 2017 en Coahuila, Nayarit y el Estado de México (donde su candidata, Delfina Gómez, sumó $30.8 \%$ del voto y sólo perdió por 2.9 puntos 
porcentuales). ${ }^{5}$ Conscientes de sus debilidades, el PRI, PAN y PRD buscaron reagruparse para competir en los comicios generales de 2018.

La recomposición de la oferta política: coaliciones y desacuerdos presidenciales

La coalición más intuitiva se perfiló entre el PRI, el PVEM y el Panal, partidos con afinidades notorias en elecciones pasadas. En esta ocasión, sin embargo, el éxito del Verde y de Nueva Alianza en algunas entidades los llevó a diversificar sus alianzas regionales y locales. Ambos también intentaron negociar su eventual participación en un Frente amplio opositor, impulsado por el PAN. Por su parte, el PRI logró evitar rupturas públicas en la selección de su candidato a la primera magistratura. Tras modificar sus estatutos para permitir la postulación de un ciudadano sin militancia formal, el secretario de Hacienda, José Antonio Meade, fue designado por una convención nacional de delegados y consiguió el apoyo de sus competidores más visibles. Finalmente, el PVEM y el Panal terminaron sumándose a su campaña e integraron la coalición Todos por México.

Sin embargo, las tensiones persistieron en la selección del resto de candidaturas y la coalición se fracturó en el ámbito subnacional. En las elecciones para senadores y diputados federales, solamente se lograron acuerdos en 17 y en 16 estados. Además de fragmentar el voto y generar confusiones entre el electorado, se rompió la unidad de la campaña presidencial oficialista. En ocasiones, las divisiones se hacieron públicas, por ejemplo, las divergencias entre las direcciones nacionales y estatales acabaron con la coalición Todos por Chiapas, formada inicialmente por el PRI, el Panal, el PVEM y

${ }^{5}$ Juan Pablo Navarrete Vela, "Desempeño de Morena en los procesos electorales de 2017”, Apuntes Electorales, Año xvII, núm. 59, julio-diciembre de 2018 . 
dos partidos locales (Mover a Chiapas y Chiapas Unido). Tras su salida, estos últimos tres partidos se sumaron brevemente a la candidatura común del PAN-PRD-MC, antes de impulsar la del aspirante ecologista, Fernando Castellanos. Éste captó 22.9\% del voto y rebasó al priista Roberto Albores Gleason (que recibió $20.2 \%$ ). De haberse mantenido la coalición inicial, es probable que hubiera derrotado al abanderado de Juntos Haremos Historia en Chiapas, Rutilio Escandón, quien ganó la gubernatura con $39.1 \%$ del sufragio.

Las rupturas fueron todavía más notables en las filas de la coalición Por México al Frente. Ésta se planteó, al principio, como un frente ciudadano amplio para impulsar candidaturas comunes entre el PAN, PRD y MC en las elecciones federales y locales. Asimismo, se abrieron negociaciones con el PVEM y el Panal, que sólo se lograron para algunas candidaturas locales. La candidatura presidencial se transformó así en la manzana de la discordia, a falta de un acuerdo sobre el método de selección, que fue criticado por varios aspirantes (entre ellos el jefe de gobierno de la Ciudad de México, Miguel Ángel Mancera). Esto dividió incluso al PAN, cuyo presidente Ricardo Anaya logró sustituir las primarias por una polémica recolección de apoyos, que fue descalificada como un "dedazo disfrazado" por sus contrincantes internos. La ruptura más sonada se produjo con la renuncia de Margarita Zavala al PAN quien, tras una larga militancia y habiendo sido la primera dama de México, optó por competir como candidata independiente.

En contraste con estas coaliciones endebles, sin bases ideológicas ni programáticas, el liderazgo incuestionado de AMLO galvanizó una sólida candidatura común en torno a Morena. Desde 2016, López Obrador declaró que su partido no buscaría alianzas para las presidenciales. Sin aspirantes propios, el PT lo registra por tercera vez como su precandidato en 2017, tal y como lo había hecho en 2006 y en 2012. El Partido Encuentro Social, en cambio, baraja distintas opciones, incluyendo a Margarita Zavala, al alcalde de Cuernavaca, Cuauhtémoc Blanco, y al presidente nacional del mismo par- 
tido, Hugo Éric Flores Cervantes. Tan sólo en diciembre de 2017, este nuevo partido de orientación evangélica terminó registrando a AMLO como su precandidato presidencial, sumándose así a la coalición Juntos Haremos Historia.

La importancia territorial de las coaliciones se observa en los resultados de las elecciones para diputados federales de 2018 en los 300 distritos uninominales. Si bien un partido del tamaño de Movimiento Ciudadano sólo aportó 4.7 puntos porcentuales del voto nacional al frente de Ricardo Anaya, en catorce distritos de Jalisco el partido de Enrique Alfaro captó un promedio de $27.5 \%$ del sufragio, es decir, el doble que el pan (13.7\%). En nueve distritos de Chiapas, el Verde Ecologista recibió, a su vez, $21.5 \%$, y le aportó más votos a México por todos que el propio PRI (que recibió 15.9\%). A su vez, el PRD apenas aportó 5.6 de los 28.2 puntos de la coalición Por México al Frente, a nivel nacional, pero en 28 distritos de Guerrero, Michoacán, San Luis Potosí, Tabasco y la Ciudad de México sus votos (19.5\%) duplicaron los del PAN $(9.6 \%)$.

En contraste, el PT, el Panal y el PES tuvieron un papel más difuso en otras entidades. El PT, por ejemplo, cuenta con un peso significativo en 37 distritos del sureste y del centro de México, así como en Zacatecas, Nayarit, Durango y Baja California, donde movilizó entre $4.6 \%$ y $19.7 \%$ del sufragio y aportó 7.9 puntos a Juntos Haremos Historia. El Panal y el PES, en cambio, sólo consiguieron resultados relevantes en veinte distritos situados en Nuevo León, así como en Ciudad Juárez, Ciudad Obregón, Culiacán, Guadalajara, Morelia, Celaya, Pachuca, Huejutla y Cuernavaca, por lo que sus aportes a las coaliciones resultan difíciles de ponderar. Por cierto, ninguno de ambos logró sumar el mínimo requerido de votos para conservar sus registros respectivos a nivel nacional (véase mapa 5). 


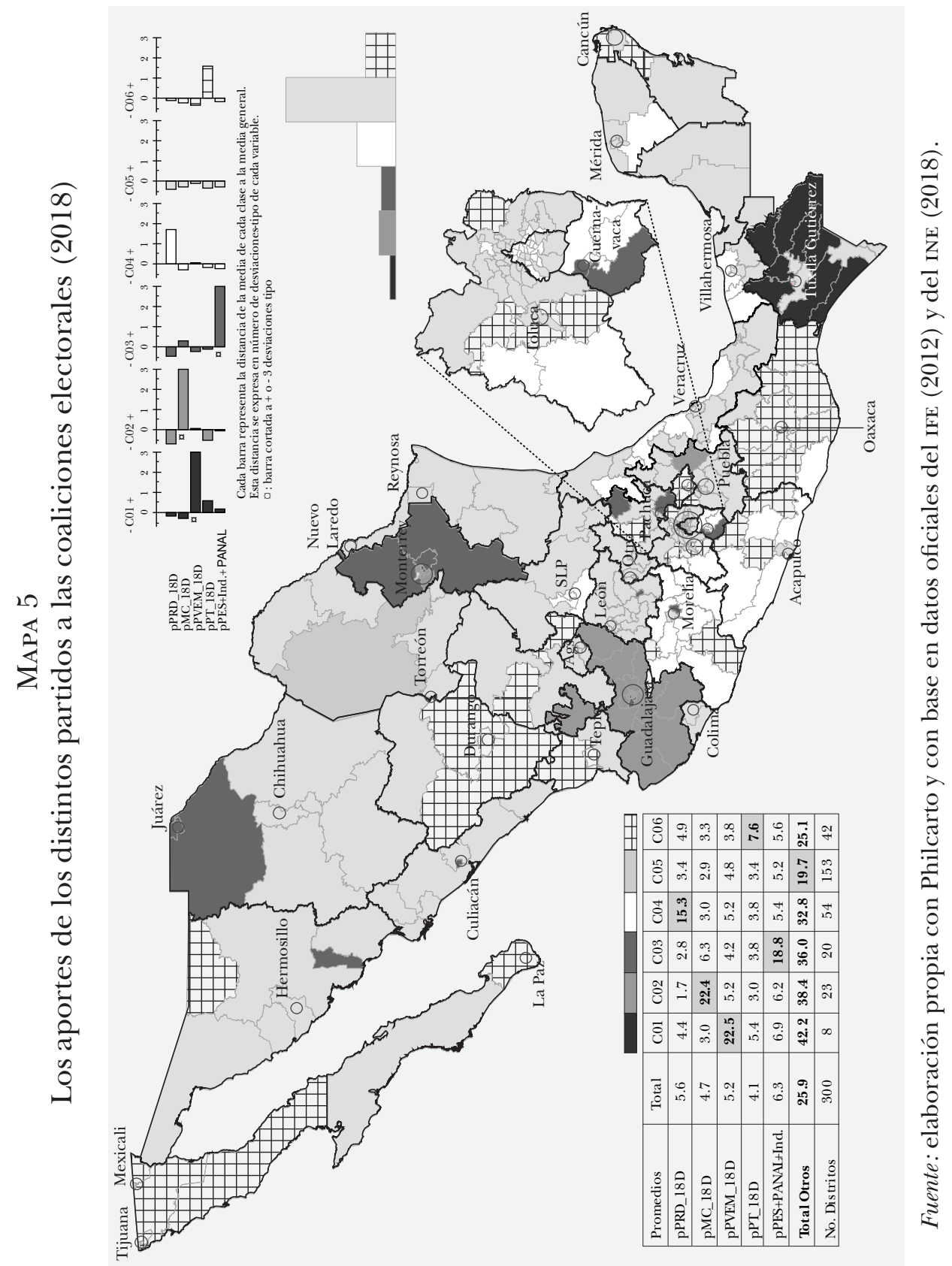


Efectos de notabilidad: el voto cruzado y estratégico, "útil" o "negativo"

Finalmente, López Obrador se benefició de un importante efecto de notabilidad personal. Mientras que los candidatos de Juntos Haremos Historia sólo registraron $45.4 \%$ del voto para diputados federales, AMLO sumó $54.8 \%$ en los presidenciales (+9.4 puntos porcentuales adicionales). El cuadro 1 sintetiza este comportamiento agregado en el nivel nacional.

Los votos cruzados provienen de los electores que votaron por algún partido de Todos por México o Por México al Frente en las legislativas, pero no sufragaron por José Antonio Meade (-7.9 puntos) ni por Ricardo Anaya (-5.3 puntos) en la presidencial, del mismo modo que 326000 ciudadanos que se abstuvieron y 637000 que anularon sus boletas en las primeras, pero sí votaron válido en la segunda. Los reportes más importantes se produjeron entre los electores del PRI y del PVEM (entre los cuales Meade perdió más de 1.63 millones de sufragios, respectivamente), mientras que los panistas votaron en forma más disciplinada y Anaya perdió, sobre todo, 1.36 millones de electores del PRD y 1.47 millones de electores del Mc. A su vez, el Bronco también captó buena parte de este voto cruzado, aunque no contaba con candidatos aliados en las legislativas.

Hay distintas formas de interpretar este peculiar comportamiento electoral. Desde una perspectiva optimista, dichos electores prefirieron la candidatura de López Obrador porque les resultaba simplemente más atractiva. Desde una óptica más académica, suele argumentarse que, en un sistema electoral con una sola vuelta presidencial, los electores mejor informados anticipan las probabilidades de victoria y votan por la candidatura con mayores posibilidades de derrotar a la que consideran menos deseable, ejerciendo así un voto "útil" por su segunda preferencia. Finalmente, también puede pensarse que el fenómeno refleja un voto "negativo", producto del rechazo de la candidatura impulsada por el partido 


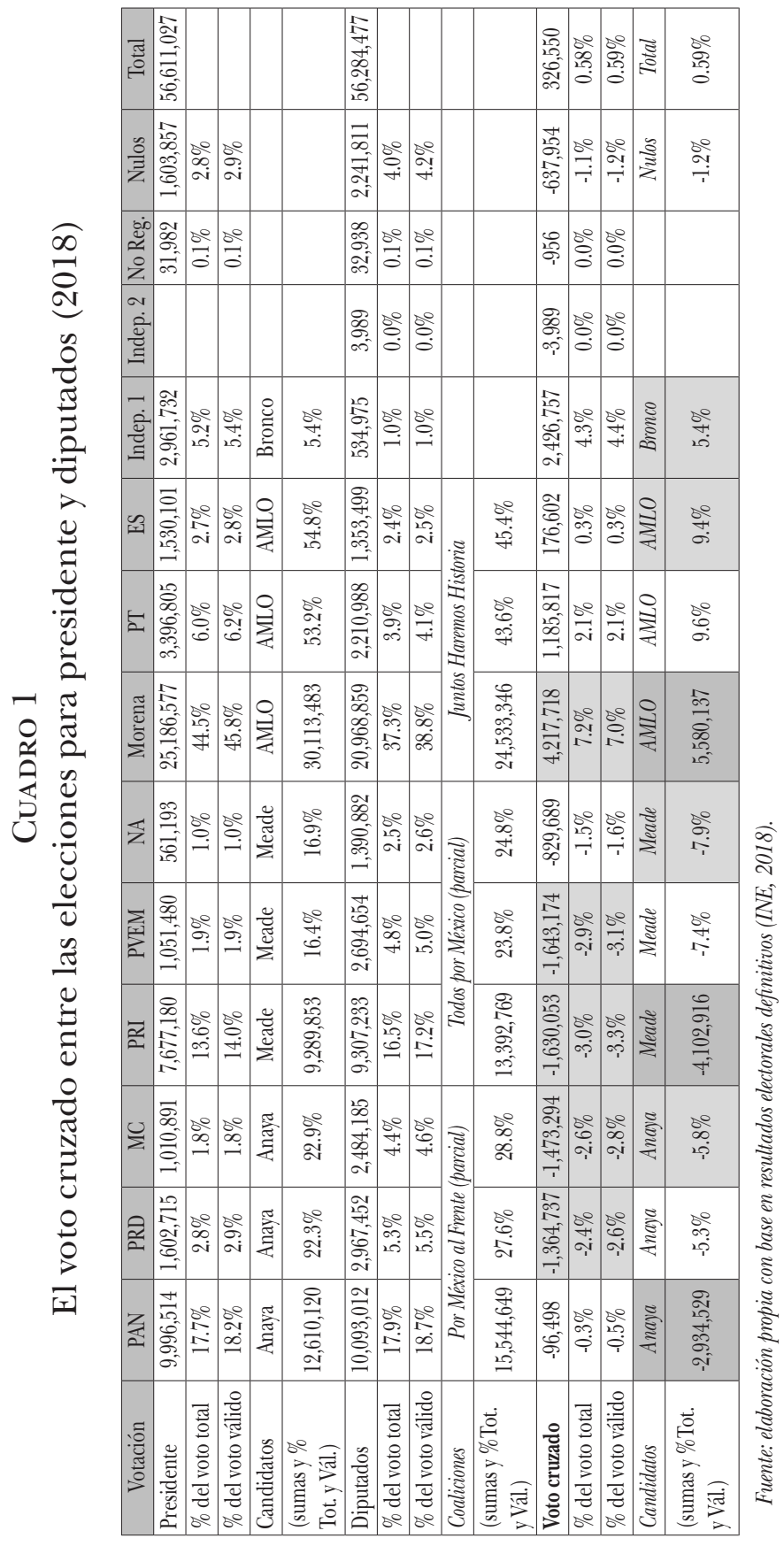


de su elección, que se reporta sobre la opción que perciben como "menos peor" en la presidencial.

Las percepciones ciudadanas de los partidos tienden a apoyar esta última interpretación. Como botón de muestra, $42 \%$ de los 13000317 encuestados por Berumen-Ipsos en junio de 2018 manifestaron que "nunca votarían" por el PRI, mientras que sólo 14\% declararon querer sufragar por los candidatos de este partido en las elecciones para diputados y $13 \%$ en la presidencial. La misma encuesta también permite indagar en las dinámicas más finas del voto cruzado, al revelar el comportamiento individual de una muestra representativa del electorado, que no se puede inferir directamente de los datos agregados. Como lo ilustra el cuadro 2, Anaya retuvo $83 \%$ de quienes declararon querer votar por el PAN en las legislativas, pero sólo captó $48 \%$ y $34 \%$ de quienes dijeron querer hacerlo por el PRD o por el MC. A su vez, Meade retuvo $82 \%$ de los electores del PRI, pero apenas captó $42 \%$ y $32 \%$ de los del PVEm y del Panal. AMLO, en contraste, no sólo retuvo 96\% de los electores de Morena, $87 \%$ del PES y $84 \%$ del PT; logró atraer $55 \%$ de los electores del MC y $40 \%$ del PRD, $42 \%$ del Panal y $35 \%$ del PVEM, e incluso $12 \%$ del PAN y $10 \%$ del PRI.

Pese a las coaliciones negociadas por las elites panistas y priistas, la candidatura de López Obrador resultó más atractiva que la de Anaya para los electores del mC y la de Meade para los del Panal, logrando dividir los electorados del PRD y del PVEM. En cuanto a la candidatura de El Bronco, ésta logró sus mejores resultados entre quienes no respondieron o declararon votar por otros partidos, o abstenerse, o anular sus votos $(11 \%)$, pero incluso sus preferencias beneficiaron a AMLO (quien captó $60 \%$ de este segmento residual).

Pero la composición del voto cruzado también varía en función de los contextos territoriales. La encuesta de Berumen-Ipsos contiene sobremuestras para las nueve entidades que eligieron gobernadores o jefe de gobierno, lo que nos permitió aproximarnos a las dinámicas diferenciadas del voto cruzado en ellas. Con la única excepción de Guanajuato, AMLO retuvo siempre más del $94 \%$ de quienes manifestaron querer 


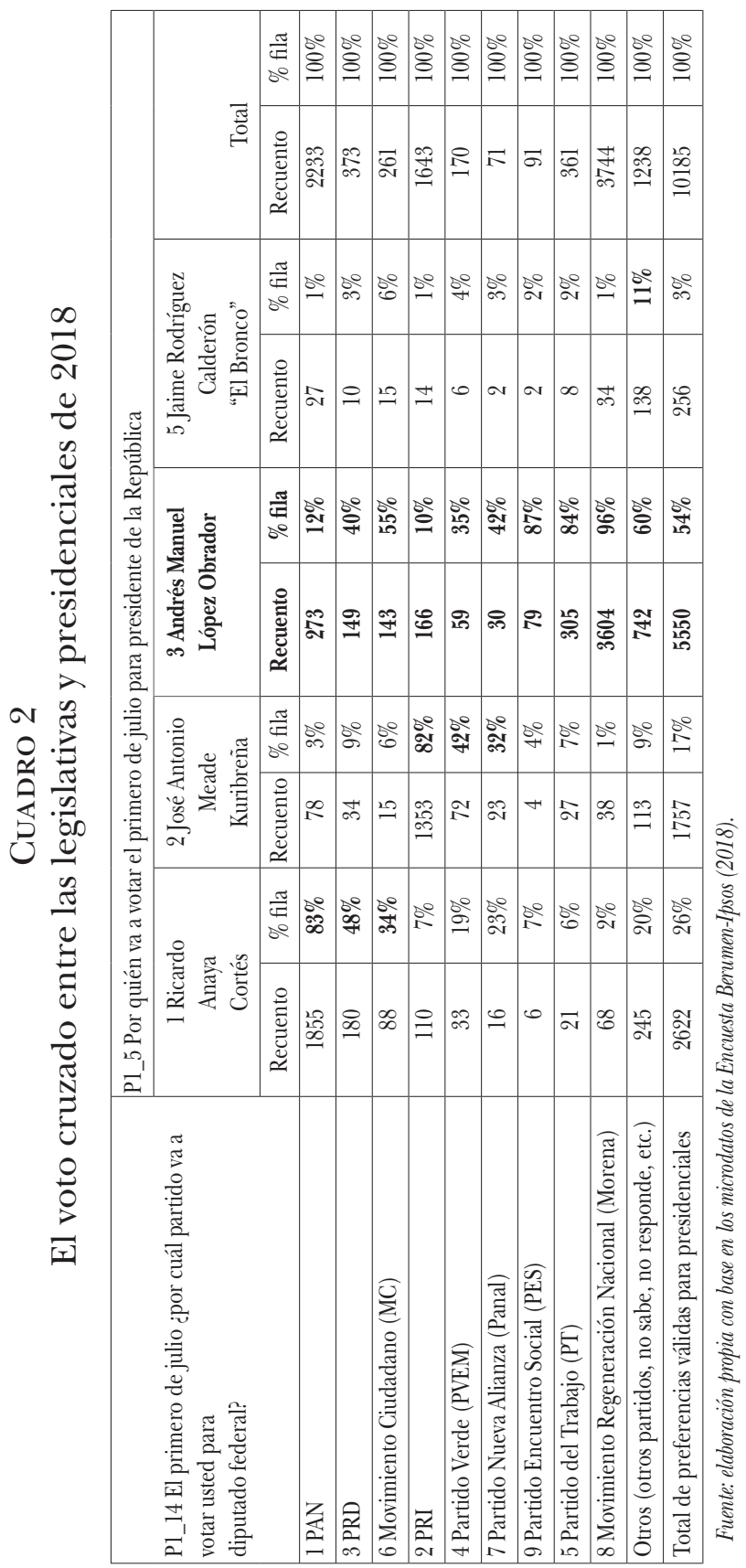




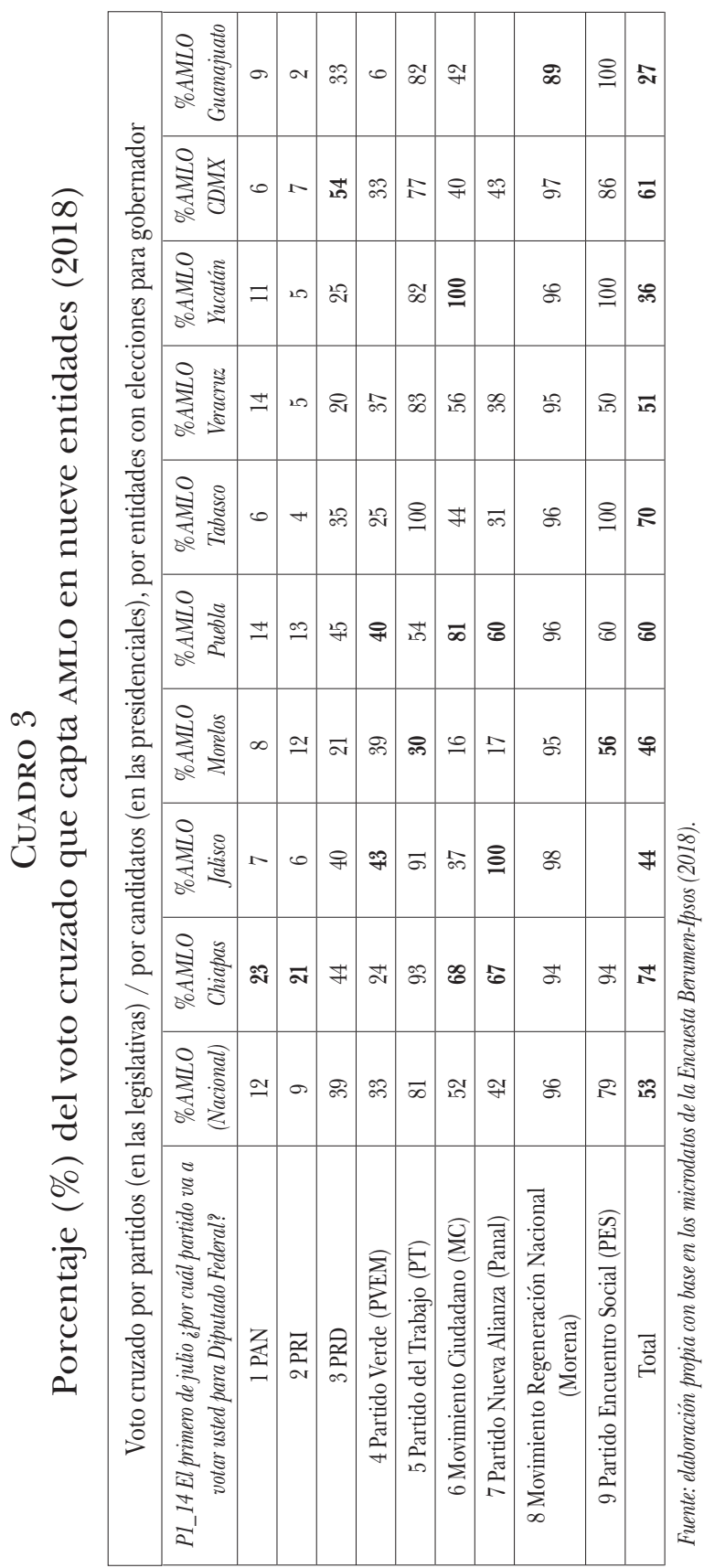


votar por Morena en las legislativas; asimismo, captó más de la mitad de los electores del PRD en la Ciudad de México y atrajo al menos a dos de cada tres electores del mc en Chiapas, Puebla y Yucatán, así como del Panal en Puebla, Chiapas y Jalisco; finalmente, atrajo a cuatro de cada diez electores del PVEM en Jalisco y en Puebla, así como $23 \%$ del PAN y $21 \%$ del PRI en Chiapas.

Finalmente, la heterogeneidad del voto cruzado puede analizarse con un enfoque geográfico, en niveles territoriales más finos. En 2018, López Obrador captó más votos que los candidatos a diputados de Juntos Haremos Historia en 97\% de las 66479 secciones electorales, sumando más de 13.2 puntos adicionales en una cuarta, y más de 18.2 puntos adicionales en una décima parte de éstas. Para simplificar las dinámicas, el mapa 6 sintetiza las principales configuraciones territoriales del voto cruzado en el nivel de los 300 distritos federales, en los que AMLo siempre obtuvo más votos que sus aliados en las legislativas. Como se observa, su composición geográfica presentó una gran variación en función del arraigo territorial de los distintos partidos políticos.

El voto cruzado alcanzó un promedio de 17.4 puntos porcentuales en catorce distritos de Morelos, Guerrero, Michoacán, San Luis Potosí y Veracruz, donde el PRD obtuvo sus mejores resultados en las legislativas $(21.1 \%)$ y Anaya perdió 10.9 puntos en las presidenciales, es decir más votos que Meade (-9.1 puntos). Algo similar sucedió en 28 distritos de Tabasco, Veracruz, Michoacán, del Estado y la Ciudad de México, donde el PRD obtuvo resultados significativos (13.7\%) y Anaya perdió 7.5 puntos en beneficio de AMLO (+8.6 puntos). Éste registró 13.5 puntos adicionales en 14 distritos más de Jalisco, donde el MC obtuvo sus mejores resultados en las legislativas y Anaya perdió 11.7 puntos en las presidenciales. Junto con los datos de la encuesta, estas configuraciones indican que las alianzas del PAN con las distintas dirigencias estatales del PRD, y con Enrique Alfaro en Jalisco, no lograron retener los votos presidenciales de muchos de sus simpatizantes (véase mapa 6). 


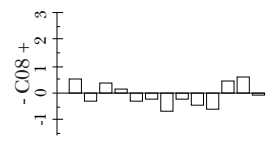

:

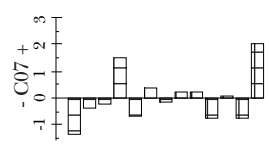

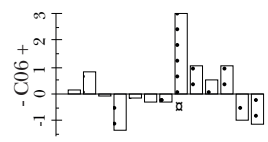
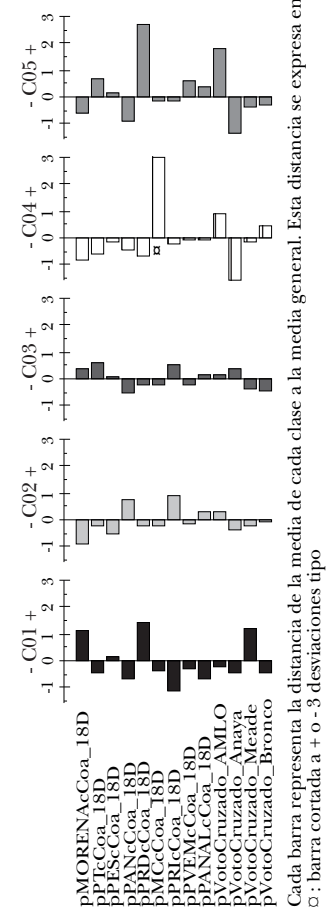

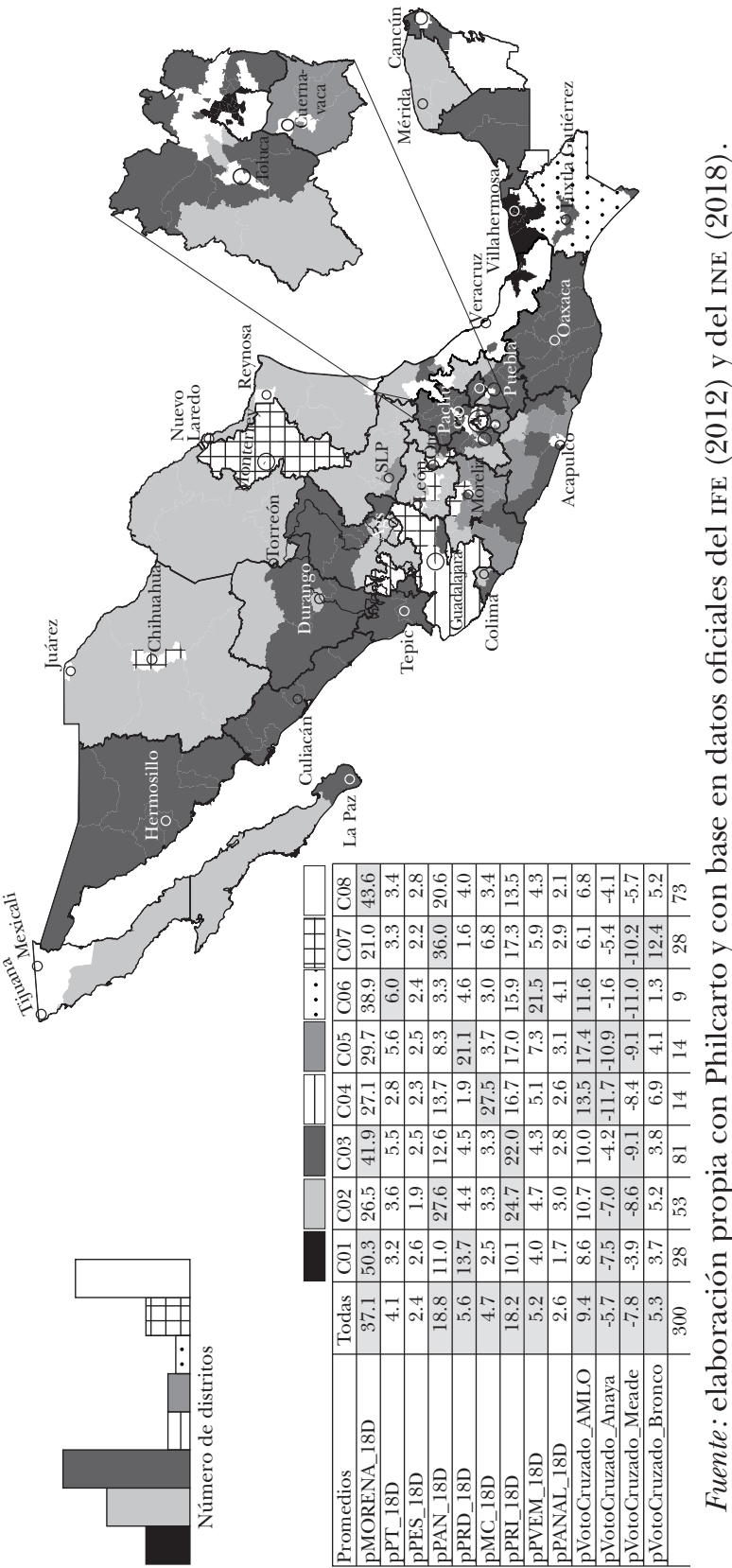


López Obrador también obtuvo un importante voto cruzado (+11.6 puntos) en nueve distritos de Chiapas, donde el PVEM sumó $21.5 \%$ en las legislativas, pero Meade perdió 11 puntos. Asimismo, Meade registró pérdidas importantes (-9.1 puntos) en 81 distritos del sureste, de la costa del Pacífico, de la región centro, de Zacatecas y Durango, que se tradujeron en ganancias para AMLO (+10 puntos). En cambio, las transferencias de votos que beneficiaron a AMLO y al Bronco (+5.2 puntos) en los 53 distritos del norte, del Bajío y de Yucatán, provienen tanto de pérdidas de Meade (-8.6 puntos) como de Anaya (-7 puntos).

El Bronco, finalmente, atrajo 12.4\% del sufragio "útil" en 28 distritos situados en Nuevo León, Nuevo Laredo y la capital de Chihuahua, así como en el famoso corredor industrial que atraviesa Aguascalientes, Jalisco, Guanajuato y Querétaro, donde se benefició sobre todo del voto de rechazo a Meade (-10.2 puntos). En cuanto a los 73 distritos restantes situados en el Estado y la Ciudad de México, en Veracruz, Tabasco y Quintana Roo, así como en Acapulco, Reynosa, Ciudad Juaréz, Mexicali y Tijuana, éstos se caracterizan por reportes más moderados. Aquí, Morena captó 43.6\% del sufragio en los comicios para diputados, beneficiándose de entrada de transferencias masivas de electores que también decidieron romper con sus antiguas lealtades partidistas en las legislativas.

\section{Una nueva geografía político-electoral}

Para terminar, cabe analizar la nueva distribución territorial de las principales fuerzas partidistas, en su dimensión potencialmente más estable y estructural. Para ello, retomemos los resultados de los comicios para diputados federales de 2018, desagregados por partidos y en el nivel distrital.

Pese a los efectos de polarización y de reconcentración del voto que generó la victoria de AMLo en las presidenciales, en las que el número efectivo de partidos electorales se redu- 
jo efectivamente a 2.6 fuerzas relevantes, persiste un elevado nivel de fragmentación partidista en las legislativas. Con todo y los efectos de arrastre del candidato presidencial de Juntos Haremos Historia, en los comicios para diputados federales Morena solamente obtuvo $38.7 \%$ del voto válido, contra $18.7 \%$ para el PAN, $17.3 \%$ para el PRI y $24.3 \%$ de los sufragios para los otros "pequeños" partidos restantes (con 5.5\% para el PRD, 5.0\% para el PVEM, $4.6 \%$ para el MC, $4.1 \%$ para el PT, $2.6 \%$ para el Panal y $2.5 \%$ para el PEs). Sin duda, tras haber alcanzado un promedio de 5.7 (con un máximo distrital de 8 partidos efectivos) en las legislativas intermedias de 2015, la fragmentación se redujo a un promedio de 4.4 partidos (con un máximo distrital de 6.6 partidos efectivos). Sin embargo, estamos muy lejos de las tasas de concentración que se registraban cuando un solo partido tenía una posición hegemónica o dominante. Los siguientes mapas sintetizan la nueva geografía electoral, que se caracteriza por marcados contrastes regionales.

Para empezar, Morena logró expandirse a lo largo y ancho del territorio nacional, aunque sigue caracterizándose por una fuerte concentración geográfica (con un índice de Moran de 0.76). Como era de esperarse, sus mejores resultados se sitúan en Tabasco, en el valle y en la Ciudad de México, pero también en algunos distritos colindantes de Oaxaca, Veracruz y Chiapas, así como en varias ciudades importantes (Cancún, Tapachula, Acapulco, Culiacán, Mexicali y Tijuana). Como si fuese efectivamente el producto de un tsunami, su crecimiento se produjo sobre todo a lo largo de las costas del Pacífico y en el sur del Golfo de México. En cambio, Morena tuvo menor éxito en el Bajío y en el noreste del país, donde solamente logró penetrar en algunas ciudades (Reynosa, Torreón, San Luis Potosí, Aguascalientes, Guadalajara, Irapuato, Salamanca y Querétaro), sin amenazar seriamente a los partidos establecidos en ellas. A decir verdad, Regeneración Nacional sólo rebasó $50 \%$ del voto en 39 distritos. Sin embargo, gracias a la debilidad y a la fragmentación del resto de los partidos, Morena obtuvo el primer lugar 
en 214 circunscripciones, transformándose así en la fuerza mayoritaria del país (véase mapa 7).

La geografía del voto panista, por su parte, contrasta directamente con este mapa. A lo largo del sexenio, Acción Nacional cedió mucho terreno, pero sí logró resistir los embates de la tormenta en muchos de sus bastiones históricos, particularmente en el corazón del Bajío (Guanajuato, Querétaro, San Luis Potosí, Aguascalientes y en el noreste de Jalisco), en Tamaulipas, en Chihuahua, en Durango y en Baja California Sur, así como en Yucatán y Veracruz (donde obtuvo buenos resultados en las ciudades capitales). Así, su declive relativo se tradujo en una concentración notable de sus votos legislativos (con un índice de Moran de 0.66). Ello le permitió conservar al menos $25 \%$ del sufragio en 85 distritos, con una mayoría relativa en 49 de ellos (véase mapa 8 ).

Como lo hemos visto, el PRI fue menos afortunado y quedó relegado al tercer lugar. Como consecuencia del desgaste del gobierno de Enrique Peña Nieto, este partido sufrió un fuerte voto de sanción y perdió la mitad de sus electores en los últimos tres años del sexenio. Ciertamente, con todo y la adversidad, el tricolor logró conservar más de $25 \%$ del voto en 56 distritos, situados en algunas zonas rurales del norte (en Sonora, Sinaloa, Chihuahua, Coahuila, Durango y Nuevo León), de Zacatecas, San Luis Potosí, Querétaro y el Estado de México, así como de Campeche y Yucatán. Sin embargo, perdió mucha fuerza en estados que se consideraban tradicionalmente como sus bastiones, particularmente en Durango, Tamaulipas y Veracruz, obteniendo la mayoría relativa en solamente 21 distritos. Esta nueva geografía del Revolucionario Institucional es más dispersa que la de Morena y del PAN (índice de Moran de 0.49) e ilustra la profundidad de la crisis del partido que gobernó el país durante más de siete décadas (véase mapa 9). 


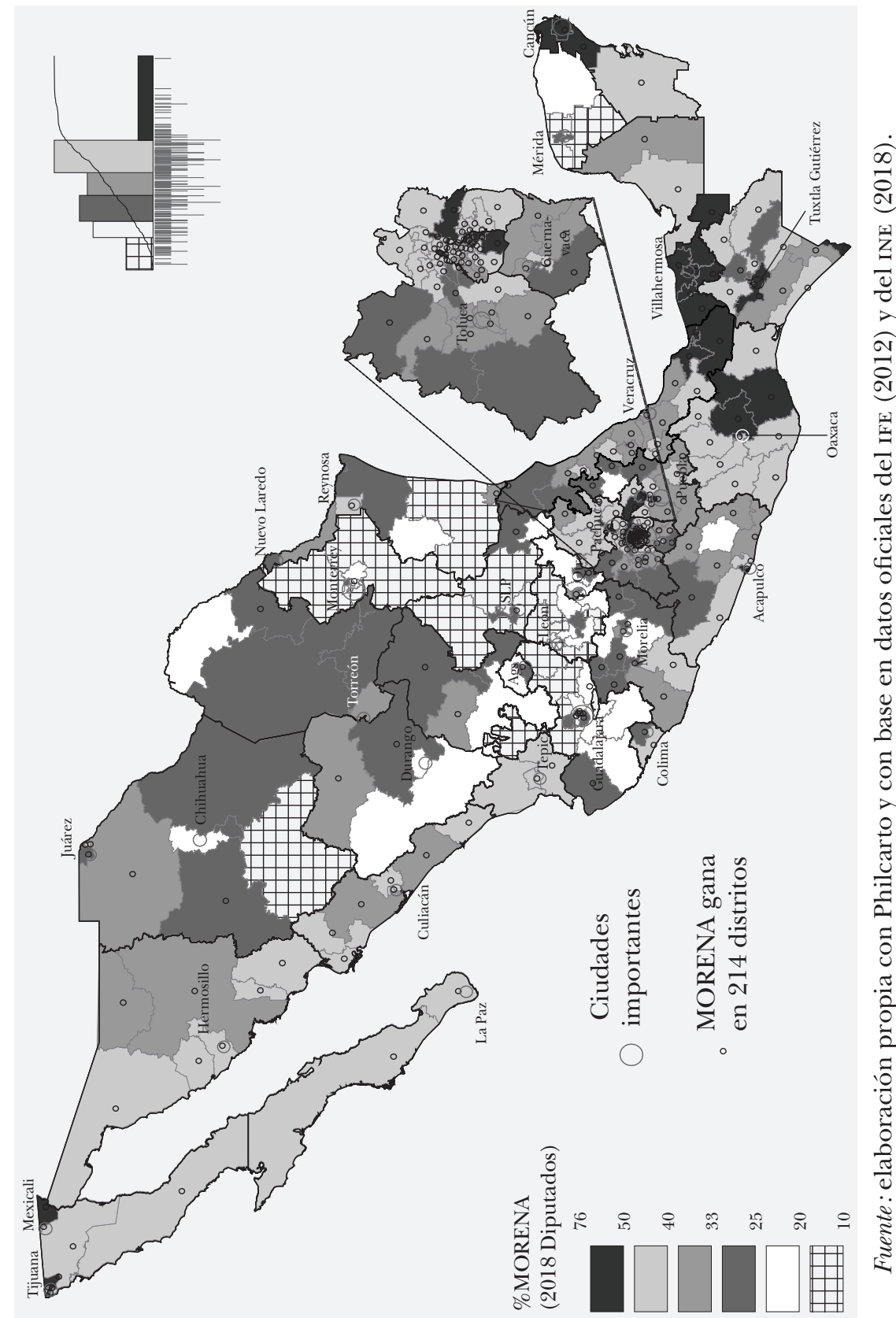

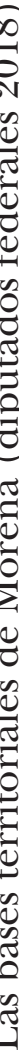

Foro Internacional (FI), LX, 2020,

núm. 2, cuad. 240, 451-500

ISSN 0185-013X; e-ISSN 2448-6523

DOI: 10.24201/fi.v60i2.2731 


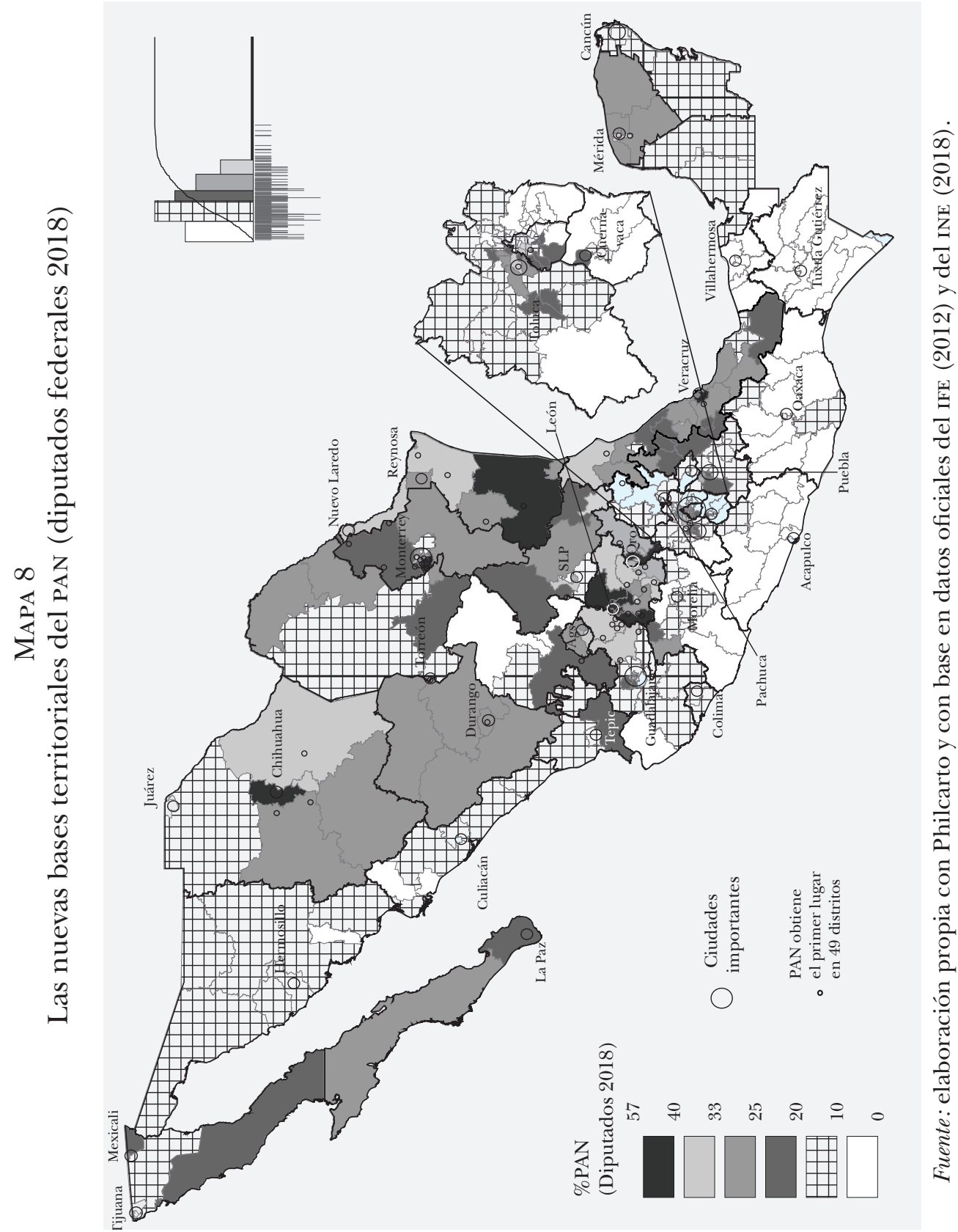




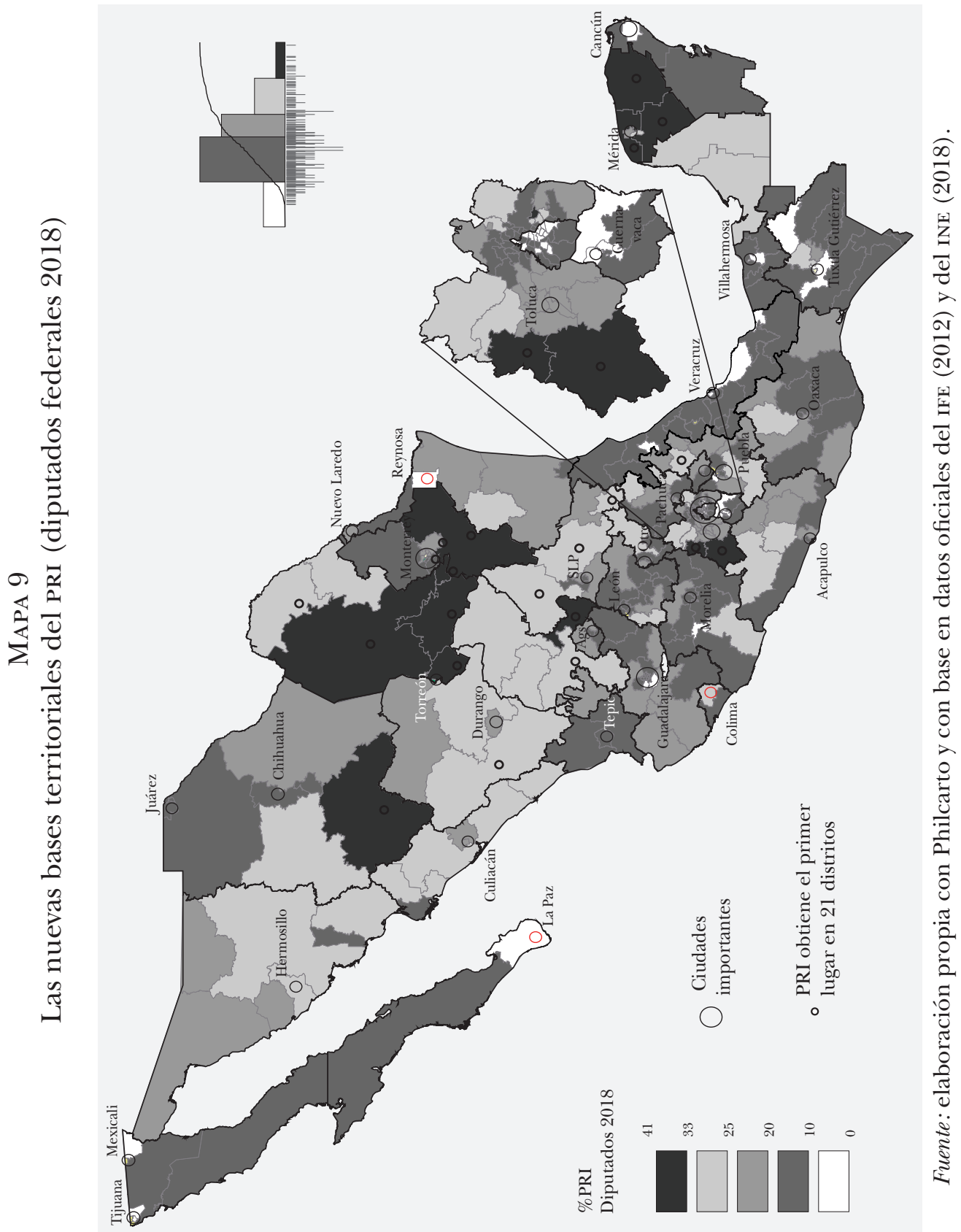




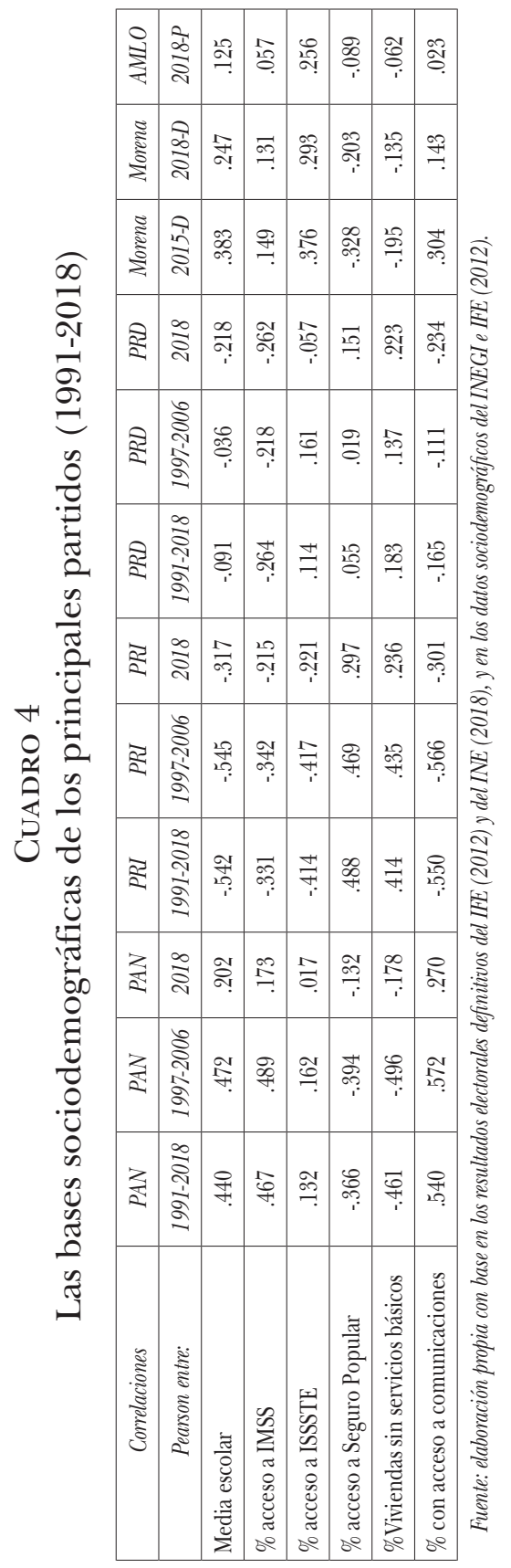


Considerando que ya analizamos la distribución distrital del resto de los partidos en el apartado dedicado a la composición geográfica de las tres coaliciones presidenciales, concluimos este recorrido con un último mapa que sintetiza la nueva correlación territorial de fuerzas entre Morena, el PAN, el PRI y el conjunto de los otros partidos. Se confirma así la posición ventajosa de Regeneración Nacional en 154 distritos de la costa norteña del Pacífico, del centro, del sureste y de la península de Yucatán, con una presencia mayoritaria en 76 de ellos (situados en Baja California, Baja California Sur y Nayarit, en la Ciudad de México, Cuernavaca y Puebla, así como en Veracruz, Tabasco, Quintana Roo y Chiapas).

Acción Nacional, en cambio, cuenta con una ventaja comparativa en 61 distritos del Bajío (particularmente en el corredor industrial que atraviesa Aguascalientes, Jalisco, Guanajuato y Querétaro), en regiones importantes de Chihuahua, Durango, Tamaulipas, Puebla y Veracruz, así como en las ciudades de Monterrey, San Luis Potosí, Toluca y Mérida. El Revolucionario Institucional, a su vez, mantiene un lugar competitivo en 40 distritos del norte, del Bajío, del centro y de Yucatán, donde se disputa el voto con el PAN y con Morena. El resto de partidos se concentra, finalmente, en los 45 distritos restantes ubicados en Chiapas, Morelos, Guerrero, Michoacán y Jalisco donde, bajo diversos liderazgos y siglas, sumaron un promedio de $43.5 \%$ del sufragio total (véase mapa 10). Lejos de concentrarse en algún partido particular, el voto legislativo de los mexicanos sigue dividiéndose así entre cuatro fuerzas relevantes, cuya composición cambia y cuya configuración territorial varía considerablemente a lo largo y ancho del territorio nacional.

Para terminar, el cuadro 4 sintetiza el cambio de las bases sociodemográficas de los principales partidos, a través de las correlaciones bilaterales entre sus porcentajes de votos y seis indicadores que captan el desarrollo socioeconómico en el nivel de las 67000 secciones electorales. Como se observa, Acción Nacional siempre tuvo mayor éxito en las 


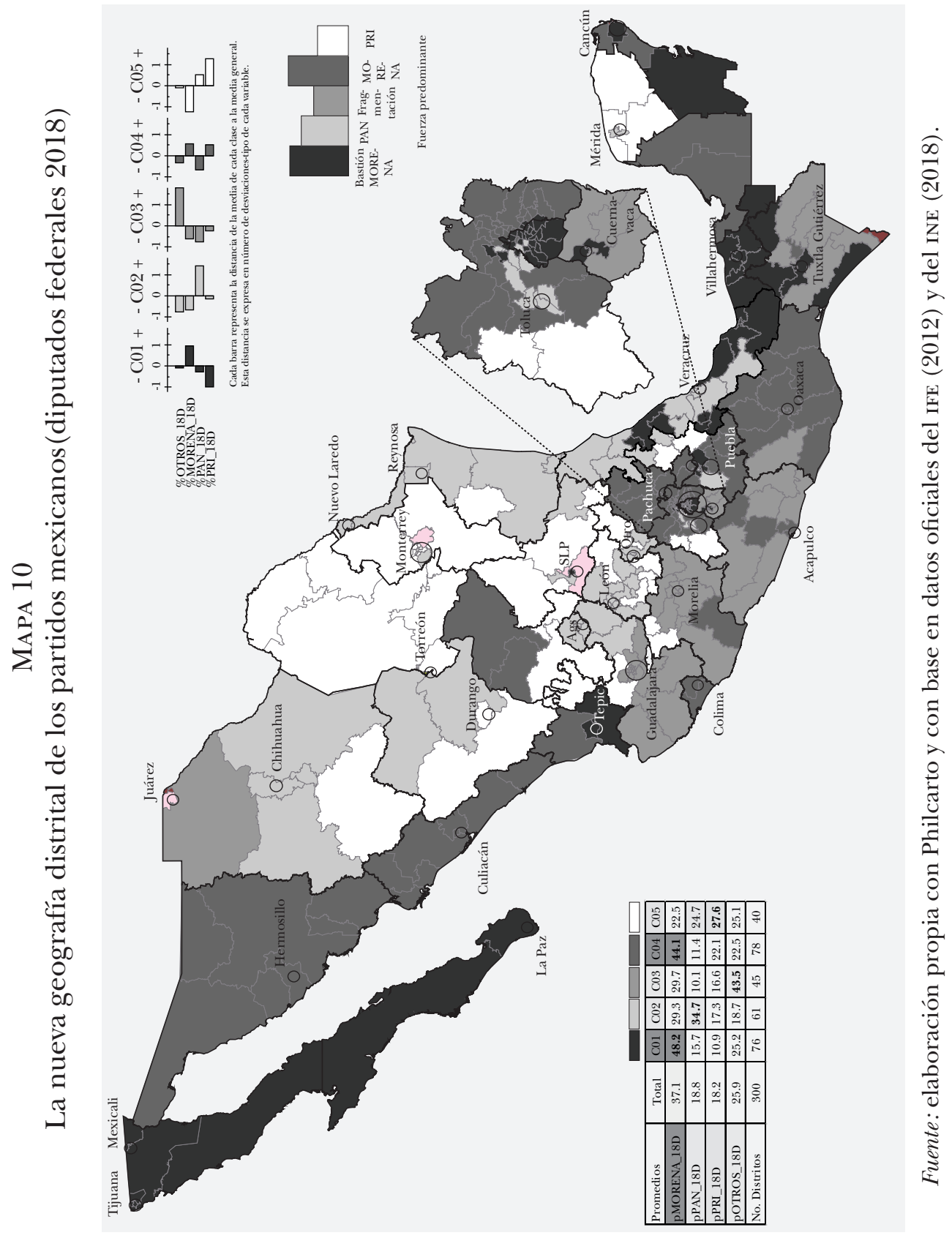


secciones con mayores niveles de educación, de viviendas con servicios básicos, de acceso al IMss y a comunicaciones, en claro contraste con el Revolucionario Institucional, cuyas bases tienen el perfil sociodemográfico opuesto. Sin embargo, la intensidad de estas correlaciones disminuye sensiblemente en 2018, lo que indica la diversificación de ambos electorados. Las bases socioterritoriales del PRD y de Morena, en cambio, son mucho más volátiles y heterogéneas porque se sitúan tanto en la franja más desarrollada del área metropolitana del valle de México, como en entidades más marginadas como Michoacán, Guerrero, Oaxaca y Tabasco. En el caso de Morena, lo que llama la atención es el cambio que se produjo entre las legislativas de 2015 y las presidenciales de 2018, con un perfil cada vez más heterogéneo e indiferenciado, del tipo "atrápalo todo" (véase cuadro 4).

DESPUÉS DEL TSUNAMI: RUPTURAS Y CONTINUIDADES DE LA REgENERACión NACIONAL

La energía de un tsunami -y sus consecuencias potencialesdepende de la magnitud del movimiento tectónico que determina su altura, la cantidad de sus picos, la longitud de su onda y la de su frente. En México, nadie ignora ya el tamaño de la ola que arrasó con las candidaturas de los partidos tradicionales el $1^{\circ}$ de julio de 2018. Ahora, la cuestión crucial consiste en establecer el número de picos y la longitud de la onda del tsunami; ello requiere averiguar qué, cuándo y dónde lo originó, para poder evaluar sus efectos duraderos una vez que se haya liberado su energía y las aguas se hayan retirado.

Es todavía temprano para establecer si el crecimiento exponencial de Morena en 2018 fue de carácter coyuntural, o si dicho movimiento logrará consolidarse como un nuevo partido mayoritario, dominante o hegemónico. Lo que queda claro, por lo pronto, es que el terremoto sacudió las bases del antiguo sistema de partidos y que éstos aun no dan seña- 
les de recuperación. Las crisis de sucesión abiertas por las derrotas de Anaya en el PAN y de Meade en el PRI no han sido resueltas y siguen aflorando, más bien, las heridas y las rupturas internas. La posible creación de un nuevo partido bajo el liderazgo de Zavala corre el riesgo de fragmentar lo que queda del panismo. En cuanto al tricolor, la polémica sobre el número real de sus militantes en el contexto de su elección interna ilustra que ha dejado de ser el partido de las grandes masas que lo sostuvieron durante largas décadas.

Como también lo muestran los resultados de los comicios locales de 2019, siguen prevaleciendo la desafección electoral y la fragmentación partidista. Las coaliciones de Morena ganaron las gubernaturas de Puebla y Baja California, no por su arraigo o por su fuerza propia, sino gracias a tasas elevadísimas de abstención y a la descomposición de los partidos tradicionales.

Pese a la crisis abierta por el fallecimiento trágico de la gobernadora recién electa, en Puebla la participación se desplomó de $65.8 \%$ a $33.4 \%$ y la coalición Morena-PT-PVEM ganó la gubernatura con $44.8 \%$ del voto válido, contra $33.2 \%$ a favor de Enrique Cárdenas Sánchez (bajo las siglas de la alianza PAN-PRD-MC). Sin embargo, Luis Miguel Barbosa Huerta sólo obtuvo 687000 sufragios tras haber sumado 1031043 votos en 2018. Como partido, Morena apenas captó 393000 votos, 22000 menos de los que sumó el PAN (cuyo candidato hubiera podido ganar si hubiese competido en alianza con el PRI, que captó 283000 y $18.5 \%$ de los votos). Después de haber movilizado a $22.5 \%$ de los inscritos -y de haber perdido la gubernatura- en 2018, en 2019 Barbosa fue así electo gobernador con el apoyo de $15 \%$ de los inscritos (de los cuales Morena apenas movilizó 8.6 puntos porcentuales).

En Baja California, la coalición Morena-PT-PVEM-Transformemos ganó, a su vez, la gubernatura con $50.6 \%$ del sufragio. Su candidato, Jaime Bonilla Valdez, arrasó con sus cinco rivales del PAN (22.9\%), del PRD (8.7\%), del MC (6.6\%), del PRI $(4.7 \%)$ y del partido local PBC $(3.6 \%)$, que compitieron cada uno por separado. No obstante, la participación solo alcanzó 
29.9\%: Morena obtuvo 43.3\% del voto válido pero apenas movilizó $12.6 \%$ de los inscritos. Lejos de comprobar la fuerza estructural de Regeneración Nacional, ambos casos son sintomáticos de un sistema de partidos en ruinas, que gira ahora en torno a un partido emergente con vocación mayoritaria y carece de una oposición articulada. Sin una oposición coherente no puede haber pesos y contrapesos, ni rendición de cuentas. Y sin contrapesos ni rendición de cuentas, lo que se pone en juego es la eficiencia de la democracia.

En ciertos aspectos, México atraviesa por una coyuntura comparable a la que vivieron Bolivia, Ecuador y Venezuela durante las primeras elecciones de Evo Morales, Rafael Correa y Hugo Chávez. Como sucedió en estos países andinos a finales de los noventa, el sistema de partidos mexicano colapsó súbitamente, sepultado bajo el desencanto y por el rechazo mayoritario del electorado.

Empero, también existen diferencias fundamentales. En contraste con dichos presidentes andinos, AMLO galvanizó un poderoso movimiento opositor, pero nunca actúo como un outsider. Con una militancia longeva que inició en el PRI y maduró en el PRD, antes de engendrar a su propio Movimiento de Regeneración Nacional, Andrés Manuel López Obrador es, más bien, el último auténtico insider de la política posrevolucionaria preneoliberal. Su liderazgo encarna los valores e ideales de aquella época dorada, cuando el priisimo impulsaba un proyecto popular de desarrollo autocentrado. Pese a los temores de sus detractores, ni el liderazgo ni el proyecto de AMLo tienen un sentido equiparable a los de Morales, Correa o Chávez. Lo que sí resulta similar, no obstante, es la intensidad de la polarización y de las rupturas internas que se están produciendo ahora entre las elites antiguas y emergentes, exaltadas o aterrorizadas por los cambios que puede acarrear la Cuarta Transformación en ciernes.

Sin que las dirigencias de los partidos tradicionales se percataran de ello, México sufrió un seísmo político de una fuerza inédita y acaba de sortear una tormenta casi perfecta de una forma democrática y pacífica, cuando ésta bien hu- 
biese podido desembocar en la elección de un filibustero o en un naufragio colectivo. Por vez primera desde 1997, el ejecutivo cuenta ahora con una mayoría legislativa para implementar políticas públicas responsables que atiendan los grandes problemas del país. En cuanto a la oposición, ha llegado el momento de reunir a las tripulaciones y reparar las embarcaciones, de ponderar la magnitud de los cambios en sus justas dimensiones y reconstruir un sistema de partidos plural, eficiente y representativo, que incluya toda la diversidad sociocultural y encauce la nueva correlación de fuerzas políticas.

\section{REFERENCIAS BIBLIOGRÁFICAS}

Instituto Federal Electoral, IFE, Atlas Electoral Federal de México (19912012), México, IFE, 2012.

Instituto Nacional de Estadística (Inegi) e Instituto Federal Electoral (IFE), Sistema Estadísticas Censales a Escalas Geoelectorales, datos del Censo de Población y Vivienda 2010 a nivel de Distrito y Sección electoral, México, 2012, http://gaia.inegi.org.mx/geoelectoral/ viewer.html

Instituto Nacional Electoral (INE), Encuestas electorales (sitio de internet), https:/ / www.ine.mx/voto-y-elecciones/encuestaselectorales/elecciones-federales-ordinarias-2017-2018-estudiosentregados/berumen-2/ (consulta del 20 de mayo de 2019).

Instituto Nacional Electoral, INE, Sistema de Consulta de la Estadística de las Elecciones Federales (Siceef), en línea: http://www.ine.mx/votoy-elecciones/resultados-electorales/ (consulta del 25 de mayo de 2019).

Minvielle, Erwann y Sid-Ahmed Souiah, L'analyse statistique et spatiale. Statistiques, cartographie, télédétection, SIG, Nantes, Éditions du temps, 2003, pp. 61-82.

Navarrete Vela, Juan Pablo, "Desempeño de Morena en los procesos electorales de 2017”, Apuntes Electorales, Año xviı, núm. 59 (julio-diciembre de 2018). 
Sonnleitner, Willibald, "Rastreando las dinámicas territoriales de la fragmentación partidista en México (1991-2015), América Latina Hoy, Revista de Ciencias Sociales, vol. 75 (abril de 2017).

Sonnleitner, Willibald, Lo que el voto se llevó. La descomposición del pacto posrevolucionario en México, México, El Colegio de México, 2018, 395 pp. 